\title{
Newsvendor competition under asymmetric cost information
}

\author{
Kemal Güler ${ }^{\mathrm{a}}$, Evren Körpeoğlu ${ }^{\mathrm{b}}$, Alper Şen ${ }^{\mathrm{c}, *}$ \\ a Department of Economics, Faculty of Economic \& Administrative Sciences, Anadolu University, Eskişehir 26470, Turkey \\ ${ }^{\mathrm{b}}$ WalmartLabs, San Bruno, CA 94066, USA \\ ${ }^{\mathrm{c}}$ Department of Industrial Engineering, Bilkent University, Bilkent, Ankara 06800, Turkey
}

\section{A R T I C L E I N F O}

\section{Article history:}

Received 25 November 2016

Accepted 18 May 2018

Available online 15 June 2018

\section{Keywords:}

Game theory

Competitive newsvendor problem

Inventory competition

Asymmetric information

\begin{abstract}
A B S T R A C T
We study the newsboy duopoly problem under asymmetric cost information. We extend the Lippman and McCardle (1997) of competitive newsboy to the case where the two firms are privately informed about their unit costs. The market demand is initially split between two firms and the excess demand for each firm is reallocated to the rival firm. We show the existence and uniqueness of a pure strategy equilibrium and characterize its structure. The equilibrium conditions have an interesting recursive structure that enables an easy computation of the equilibrium order quantities. Presence of strategic interactions creates incentives to increase order quantities for all firm types except the type that has the highest possible unit cost. Consequently, competition leads to higher total inventory in the industry. However, contrary to intuition, this is only true when the firms are non-identical. A firm's equilibrium order quantity increases with a stochastic increase in the total industry demand or with an increase in his initial allocation of the total industry demand. We demonstrate our model and results in an application in a dual-sourcing procurement setting using data that obtained from a large manufacturing company. Finally, we provide a full characterization of the equilibrium of the game for the special case of uniform demand and linear market shares.
\end{abstract}

(c) 2018 Elsevier B.V. All rights reserved.

\section{Introduction}

The newsboy problem has played a central role at the conceptual foundations of stochastic inventory theory, and variants of it have been used in analysis of decision problems - such as capacity, allocation and overbooking - under demand uncertainty. In the classical newsboy problem, a firm facing uncertain demand orders a quantity of a perishable item prior to observing demand. If the demand realization is less than the ordered quantity, then the firm will have excess inventory in hand that will perish. If demand turns out to be more than the ordered quantity, then the firm will miss the opportunity of additional profit. In the wellknown characterization, the optimal order quantity, which balances the marginal expected cost of ordering one more unit against the marginal expected revenue from satisfying an additional demand, is a critical quantile of the demand distribution.

In the standard newsboy model, strategic interactions are assumed away by taking the demand faced by a firm as a model primitive. In many practical situations, however, the details of the

\footnotetext{
* Corresponding author.

E-mail addresses: kemalgoler@anadolu.edu.tr (K. Güler), ekorpeoglu@walmartlabs.com (E. Körpeoğlu), alpersen@bilkent.edu.tr (A. Şen).
}

market interaction does matter for the order quantity decisions. Some or all of a firm's unsatisfied demand can be served by other firms offering substitutes; and, vice versa, a firm may be able to sell more than its initial market share in case the rival firm is understocked. Under such conditions, a firm's payoff depends on rival firms', as well as its own, order quantities and appropriate analysis of optimal inventory decisions requires a game theoretic approach. The resulting model, dubbed the competitive newsboy model, has been studied in the literature starting with the seminal works of Parlar (1988), studying the case where the firms' initial demands are statistically independent, and Lippman and McCardle (1997), studying the cases where the demands faced by competing firms are derived from a general class of rationing rules applied to the total industry demand.

A natural extension of the competitive newsboy analysis involves incorporating information asymmetry. Asymmetric information adds a new dimension to the competitive newsboy problem. Firms may be asymmetrically informed in a competitive newsboy setting due to two broad reasons. The firms may be privately informed about their cost and/or revenue structures. Alternatively, there may be asymmetric information regarding the market demand. Alternative specifications for the key structural elements - e.g., the nature of information asymmetry, the structure 
of the market and firm demands - span a number of interesting classes of models. Among these are models of newsboy oligopoly, and models that allow arbitrary statistical dependence in firm demands, and in cost structures.

In this paper, we study the competitive newsboy problem with asymmetric cost information. The competitive newsboy model we study is built on Parlar (1988) and Lippman and McCardle (1997). The industry demand is random. There are two firms among whom the industry demand is split. Each firm has private information about their costs. If the demand that is allocated to one firm exceeds the order quantity of that firm, a portion of the excess demand spills over to the rival firm. As standard in analysis of games of incomplete information, we use the Bayesian-Nash equilibrium as the solution concept. In a Bayesian-Nash equilibrium each player's strategy is a best response against the strategies of the competing players.

We show that a pure strategy Bayesian-Nash equilibrium exists for the newsboy duopoly with asymmetric information under a fairly general set of assumptions. When there are two firms and two possible types for each firm, we show that the presence of strategic interactions creates incentives to order more for all firm types except the type that has the highest possible unit cost, who orders as a monopolist for his portion of the demand. Therefore, competition leads to higher total inventory in the industry. However, this is not true, if the firms are identical. The equilibrium conditions have an interesting recursive structure that enables an easy computation of the equilibrium order quantities. Comparative statics analysis shows that a stochastic increase in market demand or an increase in one firm's initial allocation of the total industry demand lead to higher inventory for that firm. We finally derive a complete characterization of the equilibrium and its comparative statics for the case of uniform demand and linear split rule.

The particular version of the newsvendor competition we study here has applications in a variety of settings. For example, in many procurement environments, buyers use multiple suppliers, each of which gets a pre-determined portion of the buyer's total procurement. This is usually done to protect the buyer from supply interruptions and hold-up risk. The buyer may be a manufacturer that uses the procured item to manufacture its own good which has an uncertain demand. In some of these cases, the buyer is unwilling to commit to a quantity and only specifies the percentage of its total procurement that it will allocate to each supplier. If a particular supplier cannot make his portion of the supply entirely available, the manufacturer will turn to other suppliers which may have supply beyond their share. Since suppliers have to produce or build capacity in advance of the materialization of final demand, this leads to a newsvendor type competition among suppliers. Obviously, unit costs are private information for the suppliers in this case. In Section 4.7, we provide an application in this context using data that we collected from procurement bidding events of a large manufacturing company. The analysis shows that there can be pronounced differences in suppliers' order quantities as they consider spillover demand and private information in their decisions. In some cases, the spillover effect may be so significant that the buyer may increase its fill rate by allocating more of its demand to a higher cost supplier.

The rest of this paper is organized as follows. In Section 2, we review the related literature. In Section 3, we introduce a model of inventory competition under asymmetric information. Section 4 presents our main results on the characterization of equilibrium and comparative statics analysis. We present the full characterization of equilibrium in a parametric version of the model under uniform demand distribution and a linear split rule in Section 5. We conclude and suggest some avenues for future research in Section 6. All proofs as well as detailed derivations are contained in the Appendix.

\section{Literature review}

The literature on multiple item inventory problem with substitution dates back to the paper by McGillivray and Silver (1978). However, the role of competition has not been studied until the pioneering work of Parlar (1988). Parlar studies a competitive newsboy problem with two firms managing two substitutable items facing independent demands. A deterministic fraction of unsatisfied demand for each item can be substituted to the other item, if that item has excess stock. It is shown that a unique Nash equilibrium exists. It is also shown that total profits of two competing firms are less than that would have been obtained if they were to cooperate. Wang and Parlar (1994) and Netessine and Rudi (2003) extend the analysis of Parlar for three and $n$ firms cases, respectively.

This paper is closely related to the work of Lippman and McCardle (1997) who consider the competitive newsboy problem under a general setting with respect to how initial demands are generated and how excess demand is reallocated. It is assumed that each firm's initial demand is a result of an allocation of the industry demand which is a random variable. In deterministic rules, a specific deterministic function of the industry demand is allocated to each firm in competition. In stochastic rules, a firm's initial allocation depends on the outcome of a random variable (independent demands as in Parlar (1988) can be shown to be a special case of stochastic splitting). If a firm's initial demand exceeds its order quantity, a non-decreasing function of the excess demand is reallocated to each other firm. Lippman and McCardle (1997) show the existence of an equilibrium in the general setting. For the case of symmetric firms and continuous distributions of effective demand for each firm, they also show the uniqueness of the equilibrium. For the case of two firms, they show that competition leads to higher inventory in the system.

Since these pioneering work, inventory competition gained interest in operations research literature. Other lines of research in this area include papers that consider the effect of competition on a supplier in the upper echelon (Anupindi \& Bassok, 1999), dynamic consumer choice (Mahajan \& van Ryzin, 2003), the effect of sequential moves (Serin, 2007), reactive capacity (Li \& Ha, 2008), loss aversion (Liu, Song, \& Wu, 2013), predictably irrational behavior (Ovchinnikov, Moritz, \& Quiroga, 2015) and simultaneous price and inventory competition in revenue management (Zhao, Atkins, Hu, \& Zhang, 2017).

There are other papers in operations literature where competition carries on for multiple periods and backordering is possible. In Hall and Porteus (2000) and Liu, Shang, and Wu (2007), two firms compete on product availability which impacts the market share in future periods. However, within each period that is modeled as a newsvendor problem, no substitution occurs. Netessine, Rudi, and Wang (2006) model substitution to a competing firm in the current period as well as backordering in future periods.

To our knowledge, the only study in the operations literature that incorporates the effect of private information on horizontal competition, in particular its effect on equilibrium behavior of firms competing on inventory or product availability is by Jiang, Netessine, and Savin (2011). In their study, the players have asymmetric information about future demand. Since they assume that the demand information is limited to the support of the distribution, they follow an approach taken in the robust optimization literature and assume that the players minimize absolute regret. They show that there exists a Nash equilibrium for the game and provide a characterization. Among other results, their analysis shows that the total inventory carried by the newsvendors increases with information asymmetry and may even be larger than the maximum total demand. In addition, they show that a newsvendor may not be better off by having better information about its own demand distribution than its competitors. 
We restricted our literature review on the horizontal inventory competition. There is a vast body of operations literature where inventory competition takes place between different echelons with early work that include Cachon (2001) and Cachon and Zipkin (1999) and recent work that include Cao, Wan, and Lai (2013), Lee and Yang (2013), and Spiliotopoulou, Donohue, Gurbuz, and Heese (2018).

The asymmetric information newsvendor duopoly game we study can be transformed to a supermodular game. Supermodular games were first introduced by Topkis (1979) who show that there exists at least one pure strategy Nash equilibrium in a full information supermodular game. Milgrom and Roberts (1990) show that a large class of games in economics literature are supermodular and thus have equilibrium. Supermodularity is also used recently to study games in operations literature. Examples include Lippman and McCardle (1997), Bernstein and Federgruen (2003) and Cachon (2001). Vives (1990) uses supermodularity to show the existence of pure strategy Nash equilibrium for compact action spaces and complete separable metric type spaces. This work is extended by Athey (2001) to include a larger class of type and strategy spaces which satisfy the single crossing condition. van Zandt and Vives (2007) shows the existence of Bayesian-Nash equilibrium for supermodular asymmetric information games when type sets are discrete and action sets are continua. Our model of asymmetric information newsvendor duopoly is an instance of the general class of incomplete information games studied in van Zandt and Vives (2007).

\section{A model of newsvendor duopoly}

We consider an industry served by two firms $i=1,2$ that offer two substitutable items. Throughout, we assume that the two firms are risk-neutral.

\subsection{Industry and firm demands}

The total industry demand $D$ is a continuous positive random variable with an everywhere positive density function $g()$. Thus, the distribution function $G()$, and the survival function $\bar{G}()$, where $\bar{G}(x)=1-G(x)=\operatorname{Pr}(D \geq x)$, are strictly monotonic.

As in Lippman and McCardle (1997), demand faced by each firm is determined in a two-step rationing process. First, for any realization, $d$, of random market demand, initial market shares of the two firms are determined by a deterministic function $s$ such that firm 1 's initial market share is $s(d)$ and that of firm 2 is $\hat{s}(d)=d-s(d)$. The share function $s$ satisfies $0<s(d)<d$ for all $d$. To guarantee that both market shares are increasing in market demand realization, we assume $0<s^{\prime}(d)<1$.

A given initial market share function $s$ induces random demands faced by firm $1, D_{1}=s(D)$, and firm $2, D_{2}=\hat{s}(D)=D-$ $s(D)$. By construction, the initial demands faced by the two firms, $\left(D_{1}, D_{2}\right)$, are comonotonic since both are deterministic monotone functions of the industry demand.

In the second step, given realized market demand and the order quantities of the two firms, if firm $j$ is stocked out, then some portion, $a_{i}$, of firm $j$ 's underage goes to firm $i$. Thus, the effective demand $R_{i}$ for firm $i$ is the sum of initial allocation and the reallocation:

$R_{i}\left(Q_{j}\right)=D_{i}+a_{i}\left(D_{j}-Q_{j}\right)^{+}$.

where $(x)^{+}$denotes $\max \{x, 0\}$ and $a_{i} \in[0,1]$ for $i=1,2$ is the demand substitution rate from firm $j$ to $i$ and is assumed to be deterministic. For notational simplicity, we suppress the dependence of the effective demand on other arguments. The effective demand of firm $i, R_{i}$, is a continuous random variable and its distribution is induced by the distributions of initial demands. Effective demands
$\left(R_{1}\left(Q_{2}\right), R_{2}\left(Q_{1}\right)\right)$ are also comonotonic random variables for all values of $Q_{1}$ and $Q_{2}$.

As one of the first attempts to incorporate private information into the competitive newsvendor problem, we take the two items produced by the two firms as perfect substitutes: $a_{1}=a_{2}=1$. This assumption is primarily for reduction in model dimensions and notational economy. While this is not without loss of generality, perfect substitutes assumption is well-justified in many industrial settings. For example, in a procurement environment briefly discussed in Section 4.7, potential suppliers go through a qualification process or the buyer has very detailed specifications of all terms, so that the buyer is indifferent between the products of the two firms that are selected, and the entire demand not satisfied in one firm spills over to the other firm. We leave many interesting and important issues related to finer details of the substitution possibilities to future work. However, our main findings (equilibrium existence and qualitative features of the equilibrium) are not affected by this assumption $^{1}$.

\subsection{Cost and information structures}

Firm $i$ pays a unit cost for the items that he purchases. We take the type set of firm $i$, denoted $\mathcal{C}_{i}$, as the set of values his unit cost can take. Firm $i$ 's type is governed by a probability measure $p_{i}$ over $\mathcal{C}_{i}$. Type distributions of the two firms are independent. Each firm observes his own cost prior to deciding his order quantity, but he does not observe the other firm's cost. From firm $j$ 's perspective, firm $i$ 's unit cost is a random variable $C_{i}$ with support $\mathcal{C}_{i}$ and distribution $p_{i}$.

In this paper, we focus on the case with discrete type sets. Specifically, the unit cost of each firm can take one of two values, i.e., $\mathcal{C}_{i}=\left\{c_{i L}, c_{i H}\right\}$ with $c_{i L}<c_{i H}$. We assume that firm 1's unit cost is $c_{1 H}$ with probability $p_{1}\left(c_{1 H}\right)=p$ and $c_{1 L}$ with probability $p_{1}\left(c_{1 L}\right)=1-p_{1}\left(c_{1 H}\right)=(1-p)$ and firm 2's unit cost is $c_{2 H}$ with probability $p_{2}\left(c_{2 H}\right)=q$ and $c_{2 L}$ with probability $p_{2}\left(c_{2 L}\right)=$ $1-p_{2}\left(c_{2 H}\right)=(1-q)$. With appropriate relabeling of the players, we take $c_{1 H} \leq c_{2 H}$.

We assume that salvage prices and back-order costs are 0 . (The analysis can easily be extended to relax this assumption.) We also assume, without loss of generality, that each firm earns a normalized revenue of 1 per unit of good he sells. This normalization can be achieved by changing the unit of measurement for costs. Under this normalization, we have $c_{2 H} \leq 1$. In fact, all our results remain unchanged if one were to take per unit revenues, instead of unit costs, as the source of private information.

Finally, all elements of the model except the cost realizations are common knowledge at the time the order quantity decisions are made.

\subsection{Actions, strategies and payoffs}

For each player $i$ the order quantities are the action sets, $\mathcal{Q}_{i}=$ $\left[0, \bar{Q}_{i}\right]$, where $\bar{Q}_{i}$ is the optimal order quantity of firm $i$ assuming that he gets all of the industry demand $D$ with the smallest possible value of $c_{i}$. Finally, firm $i$ 's expected payoff is $\Pi_{i}: \mathcal{Q} \times \mathcal{C} \rightarrow \Re$ where $\mathcal{C}=\mathcal{C}_{1} \times \mathcal{C}_{2}$ and $\mathcal{Q}=\mathcal{Q}_{1} \times \mathcal{Q}_{2}$.

A pure strategy for player $i$ is a function which maps his type into his action set, $Q_{i}: \mathcal{C}_{i} \rightarrow \mathcal{Q}_{i}$ where $Q_{i}\left(c_{i}\right)$ is the strategy choice for type $c_{i}$ of player $i$. Player $i$ 's interim ${ }^{2}$ expected payoff $\Pi_{i}$ is his

\footnotetext{
${ }^{1}$ For example, by taking share functions parameterized by the substitution parameters, $z_{1}\left(D, a_{1}\right)=s(D)+a_{1} \hat{s}(D)$ and $z_{2}\left(D, a_{2}\right)=\hat{s}(D)+a_{2} s(D)$, the analysis below can be extended to the more general case.

2 The terms ex ante, interim and ex post refer to conditioning with respect to the realizations of firm types. Throughout, demand remains uncertain. That is, no new information becomes available about market demand, and, thus, all expressions are ex ante with respect to demand.
} 
expected profit conditional on his realized type $c_{i}$ and order quantity $Q$, when his rival follows the strategy $Q_{j}()$ :

$\Pi_{i}\left(c_{i}, Q\right)=E_{C_{j}}\left[\pi_{i}\left(Q, Q_{j}\left(C_{j}\right), c_{i}\right)\right]=\sum_{c_{j} \in \mathcal{C}_{j}} p_{j}\left(c_{j}\right) \pi_{i}\left(Q, Q_{j}\left(c_{j}\right), c_{i}\right)$,

where, conditional on $C_{j}=c_{j}$,

$\pi_{i}\left(Q, Q_{j}\left(c_{j}\right), c_{i}\right)=E_{R_{i}\left(Q_{j}\left(c_{j}\right)\right)}\left[\min \left\{R_{i}\left(Q_{j}\left(c_{j}\right)\right), Q\right\}\right]-c_{i} Q$

is the player's ex post profit when his unit cost is $c_{i}$ and his order quantity is $Q$.

\section{Equilibrium order quantities}

A strategy profile $Q^{*}=\left(Q_{1}^{*}(), Q_{2}^{*}()\right)$ is a Bayesian-Nash equilibrium if, for each player $i$, and each type $c_{i} \in \mathcal{C}_{i}$ of player $i$,

$Q_{i}^{*}\left(c_{i}\right) \in \arg \max _{Q \in \mathcal{Q}_{i}} \sum_{c_{j} \in \mathcal{C}_{j}} p_{j}\left(c_{j}\right) \pi_{i}\left(Q, Q_{j}\left(c_{j}\right), c_{i}\right)$.

Let $Q_{i L}=Q_{i}\left(c_{i L}\right)$ be the order quantity of player $i$ if his cost is $c_{i L}$ and let $Q_{i H}=Q_{i}\left(c_{i H}\right)$ be the order quantity of player $i$ if his cost is $c_{i H}$. Let $\left(Q_{1 L}^{*}, Q_{1 H}^{*}, Q_{2 L}^{*}, Q_{2 H}^{*}\right)$ denote a Bayesian-Nash equilibrium. Interim expected payoffs conditional on own cost realizations are:

$$
\begin{aligned}
\Pi_{1}\left(c_{1 L}, Q_{1 L}\right)= & q E\left[\min \left\{R_{1}\left(Q_{2 H}\right), Q_{1 L}\right\}\right] \\
& +(1-q) E\left[\min \left\{R_{1}\left(Q_{2 L}\right), Q_{1 L}\right\}\right]-c_{1 L} Q_{1 L}, \\
\Pi_{1}\left(c_{1 H}, Q_{1 H}\right)= & q E\left[\min \left\{R_{1}\left(Q_{2 H}\right), Q_{1 H}\right\}\right] \\
& +(1-q) E\left[\min \left\{R_{1}\left(Q_{2 L}\right), Q_{1 H}\right\}\right]-c_{1 H} Q_{1 H}, \\
\Pi_{2}\left(c_{2 L}, Q_{2 L}\right)= & p E\left[\min \left\{R_{2}\left(Q_{1 H}\right), Q_{2 L}\right\}\right] \\
& +(1-p) E\left[\min \left\{R_{2}\left(Q_{1 L}\right), Q_{2 L}\right\}\right]-c_{2 L} Q_{2 L}, \\
\Pi_{2}\left(c_{2 H}, Q_{2 H}\right)= & p E\left[\min \left\{R_{2}\left(Q_{1 H}\right), Q_{2 H}\right\}\right] \\
& +(1-p) E\left[\min \left\{R_{2}\left(Q_{1 L}\right), Q_{2 H}\right\}\right]-c_{2 H} Q_{2 H} .
\end{aligned}
$$

A standard property of newsvendor models is that $\partial E_{R}[\min \{R, Q\}] / \partial Q=\operatorname{Pr}(R \geq Q)$. Thus, taking the derivative of each type's payoff with respect to his action, the BayesianNash equilibrium order quantities $\left(Q_{1 L}^{*}, Q_{1 H}^{*}, Q_{2 L}^{*}, Q_{2 H}^{*}\right)$ satisfy the following conditions:

$$
\begin{aligned}
& q \operatorname{Pr}\left(R_{1}\left(Q_{2 H}\right) \geq Q_{1 L}\right)+(1-q) \operatorname{Pr}\left(R_{1}\left(Q_{2 L}\right) \geq Q_{1 L}\right)-c_{1 L}=0, \\
& q \operatorname{Pr}\left(R_{1}\left(Q_{2 H}\right) \geq Q_{1 H}\right)+(1-q) \operatorname{Pr}\left(R_{1}\left(Q_{2 L}\right) \geq Q_{1 H}\right)-c_{1 H}=0, \\
& p \operatorname{Pr}\left(R_{2}\left(Q_{1 H}\right) \geq Q_{2 L}\right)+(1-p) \operatorname{Pr}\left(R_{2}\left(Q_{1 L}\right) \geq Q_{2 L}\right)-c_{2 L}=0, \\
& p \operatorname{Pr}\left(R_{2}\left(Q_{1 H}\right) \geq Q_{2 H}\right)+(1-p) \operatorname{Pr}\left(R_{2}\left(Q_{1 L}\right) \geq Q_{2 H}\right)-c_{2 H}=0 .
\end{aligned}
$$

Note that when the price $\left(w_{i}\right)$, salvage value $\left(v_{i}\right)$ and backorder cost $\left(g_{i}\right)$ are non-zero, Eqs. $(1,4)$ can be easily extended using a general newsvendor approach. In this case, the last term on the left-hand-side of Eqs. $(1,4)$ needs to be equal to $c_{o} /\left(c_{u}+c_{0}\right)$ where $c_{0}$ is cost of overage per unit and $c_{u}$ is cost of underage per unit. For example, for Eq. (1), the last term will be equal to $\left(c_{1 L}-v_{1}\right) /\left(w_{1}+g_{1}-v_{1}\right)$.

Note also that the type space $\mathcal{C}_{i}$ for each firm can be extended to incorporate more general discrete probability distributions. For example, for each firm's cost may take one of three values: low $\left(c_{i L}\right)$, medium $\left(c_{i M}\right)$ and high $\left(c_{i H}\right)$ with different probabilities leading to now nine equations rather than the four in $(1,4)$. While this extension complicates the notation and further analysis and lead to different mathematical expressions for equilibrium characterization, structural results and insights are not expected to be substantially different as is the case in most game theory applications (for a rare exception, see Kerschbamer \& Maderner, 1998. Therefore, we leave this extension for future work in this area.

\subsection{Equilibrium existence}

Equilibrium exists under more general assumptions than we make. For instance, the theorem below is valid for arbitrary type sets, not only discrete types. Furthermore, as noted by Lippman and McCardle (1997) in their model of complete information, the existence of equilibrium does not require any assumption on the split functions, or on the joint distribution of the initial demands.

van Zandt and Vives (2007) show the existence of BayesianNash equilibrium for supermodular asymmetric information games when type sets are discrete and action sets are continua. Our model of asymmetric information newsvendor duopoly is an instance of the general class of incomplete information games studied in van Zandt and Vives (2007). To establish the existence of pure strategy equilibrium we verify that the equilibrium existence conditions in van Zandt and Vives (2007) are satisfied in our setting. These conditions are: (i) the payoff function $\pi_{i}$ is supermodular in $Q_{i}$, (ii) it has increasing differences in $\left(Q_{i}, Q_{j}\right)$, and (iii) it has increasing differences in $\left(Q_{i}, t_{i}\right)$, where $t_{i}=-c_{i}$.

Theorem 1. A pure strategy Nash equilibrium exists for the newsvendor duopoly game with asymmetric information.

\subsection{Preliminary observations on the equilibrium}

In characterizing the structure of equilibrium, some preliminary remarks will be useful. We start with some observations on the best response functions. We then examine optimal order quantities in the absence of strategic interactions to establish a baseline.

Our first claim exploits the assumption that the split functions $s(\cdot)$ and $\hat{s}(\cdot)$ are deterministic and increasing, thus invertible.

Claim 1. $\min \left\{s^{-1}(x), \hat{s}^{-1}(y)\right\} \leq x+y \leq \max \left\{s^{-1}(x), \hat{s}^{-1}(y)\right\}$.

The best response functions of the two types of firm 1, $\left(Q_{1 L}^{*}\left(Q_{2 L}, Q_{2 H}\right), Q_{1 H}^{*}\left(Q_{2 L}, Q_{2 H}\right)\right)$, and those of firm 2, $\left(Q_{2 L}^{*}\left(Q_{1 L}, Q_{1 H}\right), Q_{2 H}^{*}\left(Q_{1 L}, Q_{1 H}\right)\right)$, solve:

$q \operatorname{Pr}\left(R_{1}\left(Q_{2 H}\right) \geq Q_{1 L}^{*}\right)+(1-q) \operatorname{Pr}\left(R_{1}\left(Q_{2 L}\right) \geq Q_{1 L}^{*}\right)-c_{1 L}=0$,

$q \operatorname{Pr}\left(R_{1}\left(Q_{2 H}\right) \geq Q_{1 H}^{*}\right)+(1-q) \operatorname{Pr}\left(R_{1}\left(Q_{2 L}\right) \geq Q_{1 H}^{*}\right)-c_{1 H}=0$,

$p \operatorname{Pr}\left(R_{2}\left(Q_{1 H}\right) \geq Q_{2 L}^{*}\right)+(1-p) \operatorname{Pr}\left(R_{2}\left(Q_{1 L}\right) \geq Q_{2 L}^{*}\right)-c_{2 L}=0$,

$p \operatorname{Pr}\left(R_{2}\left(Q_{1 H}\right) \geq Q_{2 H}^{*}\right)+(1-p) \operatorname{Pr}\left(R_{2}\left(Q_{1 L}\right) \geq Q_{2 H}^{*}\right)-c_{2 H}=0$.

Since $R_{i}(Q)$ and, hence, $\operatorname{Pr}\left(R_{i}(Q) \geq Q_{i}\right)$ are non-increasing in $Q$ best response functions for both types of both players are nonincreasing in both arguments.

Stand-alone order quantities in the absence of competitive interactions will play a useful role as a baseline. We denote by $\left(Q_{1 L}^{o}, Q_{1 H}^{o}, Q_{2 L}^{o}, Q_{2 H}^{o}\right)$ the vector of optimal order quantities for the case with no spillovers (i.e., no competitive interaction).

Lemma 1. The vector of stand-alone order quantities $\left(Q_{1 L}^{o}, Q_{1 H}^{o}, Q_{2 L}^{o}, Q_{2 H}^{o}\right)$ is the unique solution to the system of equations:

$$
\begin{aligned}
& \operatorname{Pr}\left(D_{1} \geq Q_{1 L}\right)=c_{1 L}, \quad \operatorname{Pr}\left(D_{1} \geq Q_{1 H}\right)=c_{1 H}, \\
& \operatorname{Pr}\left(D_{2} \geq Q_{2 L}\right)=c_{2 L}, \quad \operatorname{Pr}\left(D_{2} \geq Q_{2 H}\right)=c_{2 H} .
\end{aligned}
$$

The ranking of optimal order quantities of the two types of a player is straightforward - the higher a firms' unit cost the lower his stand-alone order quantity: $Q_{1 L}^{o} \geq Q_{1 H}^{o}$ and $Q_{2 L}^{o} \geq Q_{2 H}^{o}$.

In contrast, comparison of the order quantities across firms is complicated by the fact that relative rankings of the firms' market shares and unit costs are not a priori restricted. In general, depending on the relative orderings of market shares and unit costs, all rankings of the four order quantities $\left(Q_{1 L}^{o}, Q_{1 H}^{o}, Q_{2 L}^{o}, Q_{2 H}^{o}\right)$ that are compatible with the orderings $Q_{1 L}^{o} \geq Q_{1 H}^{o}$ and $Q_{2 L}^{o} \geq Q_{2 H}^{o}$ are possible. 
One needs further assumptions on market shares and unit costs to be able to rank the stand-alone order quantities of the two firms. For example, if unit costs and initial market shares are perfectly negatively correlated (so that the initial market share of the firm with the lower unit cost exceeds that of the firm with higher unit cost for all demand realizations) then stand-alone order quantities are ordered in the same way as initial market shares.

Note, on the other hand, that stock-out levels, $\left(\operatorname{Pr}\left(D_{i} \geq Q_{i x}^{o}\right): i \in\right.$ $\{1,2\}, x \in\{L, H\})$, are ordered the same way as the unit costs. This simple observation, combined with our assumption that initial demands of the two firms are monotone functions of a common market demand, allows a complete ordering of the transformed order quantities:

Claim 2. For $x, y \in\{L, H\}, s^{-1}\left(Q_{1 x}^{o}\right) \geq \hat{s}^{-1}\left(Q_{2 y}^{o}\right)$ if and only if $c_{1 x} \leq c_{2 y}$.

Returning to the analysis of the equilibrium conditions, we first note an observation on the stock-out probability of firm $i$ with order level $Q_{i}$. For firm 1:

$$
\begin{aligned}
\operatorname{Pr}\left(R_{1}\left(Q_{2}\right) \geq Q_{1}\right)= & \operatorname{Pr}\left(D_{1}+\left(D_{2}-Q_{2}\right)^{+} \geq Q_{1}\right) \\
= & \operatorname{Pr}\left(s(D)+\left(\hat{s}(D)-Q_{2}\right)^{+} \geq Q_{1}\right) \\
= & \operatorname{Pr}\left(D \geq \hat{s}^{-1}\left(Q_{2}\right), D \geq Q_{1}+Q_{2}\right) \\
& +\operatorname{Pr}\left(D \leq \hat{s}^{-1}\left(Q_{2}\right), D \geq s^{-1}\left(Q_{1}\right)\right) .
\end{aligned}
$$

Similarly, for firm 2:

$$
\begin{aligned}
\operatorname{Pr}\left(R_{2}\left(Q_{1}\right) \geq\right. & \left.Q_{2}\right)=\operatorname{Pr}\left(D_{2}+\left(D_{1}-Q_{1}\right)^{+} \geq Q_{2}\right) \\
= & \operatorname{Pr}\left(\hat{s}(D)+\left(s(D)-Q_{1}\right)^{+} \geq Q_{2}\right) \\
= & \operatorname{Pr}\left(D \geq s^{-1}\left(Q_{1}\right), D \geq Q_{2}+Q_{1}\right) \\
& +\operatorname{Pr}\left(D \leq s^{-1}\left(Q_{1}\right), D \geq \hat{s}^{-1}\left(Q_{2}\right)\right) .
\end{aligned}
$$

Second, we observe that low-cost type of each player orders a larger quantity than his high-cost type in equilibrium.

Claim 3. (i) $Q_{1 L}^{*}>Q_{1 H}^{*}$, (ii) $Q_{2 L}^{*}>Q_{2 H}^{*}$.

Using stand-alone order quantities as a baseline, the next claim shows that order quantities strictly less than the stand-alone order quantities are dominated. Thus, presence of spillovers leads to order quantities that are no less than the order quantities without spillovers. This means that total industry inventory does not decrease due to strategic behavior considering spillover demand.

Claim 4. (i) $Q_{1 L}^{*} \geq Q_{1 L}^{o}$, (ii) $Q_{1 H}^{*} \geq Q_{1 H}^{o}$, (iii) $Q_{2 L}^{*} \geq Q_{2 L}^{o}$, (iv) $Q_{2 H}^{*} \geq$ $Q_{2 H}^{o}$.

The following lemma identifies a useful boundary condition that ties the equilibrium order quantity of one of the players to the stand-alone order quantity for the high-cost type of that player.

Lemma 2. In a Bayesian-Nash equilibrium either (i) $Q_{2 H}^{*}=Q_{2 H}^{o}$ or (ii) $Q_{1 H}^{*}=Q_{1 H}^{o}$.

Next, equilibrium order quantities of high-cost types of the two firms are ordered up to transformation by initial market shares:

Lemma 3. $s^{-1}\left(Q_{1 H}^{*}\right) \geq \hat{s}^{-1}\left(Q_{2 H}^{*}\right)$.

Finally, in equilibrium, the firm with highest possible unit cost orders his optimal quantity under no competition.

Lemma 4. $Q_{2 H}^{*}=Q_{2 H}^{o}$.

When $c_{1 H}=c_{2 H}$, high-cost types of both firms order their optimal quantities under no competition, i.e., $Q_{2 H}^{*}=Q_{2 H}^{o}$ and $Q_{1 H}^{*}=$ $Q_{1 H}^{o}$.

As a final observation, we note that the best response function of the second firm's high-cost type is flat at its stand-alone level when the order quantities of the first firm's two types exceed their respective stand-alone levels:

Lemma 5. $Q_{2 H}^{*}(x, y)=Q_{2 H}^{o}$ for all $(x, y) \geq\left(Q_{1 L}^{o}, Q_{1 H}^{o}\right)$.

\subsection{Structure of the equilibrium}

Summarizing the observations in the previous sub-section, under the player labeling with $c_{1 H} \leq c_{2 H}$, the conditions for equilibrium can be stated as follows:

$$
\begin{aligned}
q \operatorname{Pr}\left(R_{1}\left(\hat{s}\left(\bar{G}^{-1}\left(c_{2 H}\right)\right)\right)\right. & \left.\geq Q_{1 L}^{*}\right)+(1-q) \operatorname{Pr}\left(R_{1}\left(Q_{2 L}^{*}\right) \geq Q_{1 L}^{*}\right)=c_{1 L}, \\
q \operatorname{Pr}\left(R_{1}\left(\hat{s}\left(\bar{G}^{-1}\left(c_{2 H}\right)\right)\right)\right. & \left.\geq Q_{1 H}^{*}\right)+(1-q) \operatorname{Pr}\left(R_{1}\left(Q_{2 L}^{*}\right) \geq Q_{1 H}^{*}\right)=c_{1 H}, \\
p \operatorname{Pr}\left(R_{2}\left(Q_{1 H}^{*}\right)\right. & \left.\geq Q_{2 L}^{*}\right)+(1-p) \operatorname{Pr}\left(R_{2}\left(Q_{1 L}^{*}\right) \geq Q_{2 L}^{*}\right)=c_{2 L}, \\
Q_{2 H}^{*} & =\hat{s}\left(\bar{G}^{-1}\left(c_{2 H}\right)\right) .
\end{aligned}
$$

We can now state the main theorem of this paper that characterizes the structure of equilibrium order quantities.

Theorem 2. $\left(Q_{1 L}^{*}, Q_{1 H}^{*}, Q_{2 L}^{*}, Q_{2 H}^{*}\right)$ is a Bayesian-Nash equilibrium if and only if

(1) $Q_{2 H}^{*}=\hat{s}\left(\bar{G}^{-1}\left(c_{2 H}\right)\right)$

(2) $Q_{1 L}^{*}, Q_{1 H}^{*}$ and $Q_{2 L}^{*}$ satisfy one of the following sets of conditions:

(i) $q \bar{G}\left(Q_{1 L}^{*}+\hat{s}\left(\bar{G}^{-1}\left(c_{2 H}\right)\right)\right)+(1-q) \bar{G}\left(s^{-1}\left(Q_{1 L}^{*}\right)\right)=c_{1 L}$

$q \bar{G}\left(Q_{1 H}^{*}+\hat{s}\left(\bar{G}^{-1}\left(c_{2 H}\right)\right)\right)+(1-q) \bar{G}\left(s^{-1}\left(Q_{1 H}^{*}\right)\right)=c_{1 H}$

$p \bar{G}\left(Q_{2 L}^{*}+Q_{1 H}^{*}\right)+(1-p) \bar{G}\left(Q_{2 L}^{*}+Q_{1 L}^{*}\right)=c_{2 L}$

$\hat{s}^{-1}\left(Q_{2 L}^{*}\right) \geq s^{-1}\left(Q_{1 L}^{*}\right)$

(ii) $q \bar{G}\left(Q_{1 L}^{*}+\hat{s}\left(\bar{G}^{-1}\left(c_{2 H}\right)\right)\right)+(1-q) \bar{G}\left(Q_{2 L}^{*}+Q_{1 L}^{*}\right)=c_{1 L}$

$q \bar{G}\left(Q_{1 H}^{*}+\hat{s}\left(\bar{G}^{-1}\left(c_{2 H}\right)\right)\right)+(1-q) \bar{G}\left(s^{-1}\left(Q_{1 H}^{*}\right)\right)=c_{1 H}$

$p \bar{G}\left(Q_{2 L}^{*}+Q_{1 H}^{*}\right)+(1-p) \bar{G}\left(\hat{s}^{-1}\left(Q_{2 L}^{*}\right)\right)=c_{2 L}$

$s^{-1}\left(Q_{1 L}^{*}\right)>\hat{s}^{-1}\left(Q_{2 L}^{*}\right) \geq s^{-1}\left(Q_{1 H}^{*}\right)$

(iii) $q \bar{G}\left(Q_{1 L}^{*}+\hat{s}\left(\bar{G}^{-1}\left(c_{2 H}\right)\right)\right)+(1-q) \bar{G}\left(Q_{1 L}^{*}+\hat{s}\left(\bar{G}^{-1}\left(c_{2 L}\right)\right)\right)=c_{1 L}$

$q \bar{G}\left(Q_{1 H}^{*}+\hat{s}\left(\bar{G}^{-1}\left(c_{2 H}\right)\right)\right)+(1-q) \bar{G}\left(Q_{1 H}^{*}+\hat{s}\left(\bar{G}^{-1}\left(c_{2 L}\right)\right)\right)=c_{1 H}$

$Q_{2 L}^{*}=\hat{s}\left(\bar{G}^{-1}\left(c_{2 L}\right)\right)$

$S^{-1}\left(Q_{1 H}^{*}\right)>\hat{s}^{-1}\left(Q_{2 L}^{*}\right)$

Before we proceed with discussion of properties of the equilibrium, we first show that it is unique.

Theorem 3. The vector of order quantities $\left(Q_{1 L}^{*}, Q_{1 H}^{*}, Q_{2 L}^{*}, Q_{2 H}^{*}\right)$ in Theorem 2 is unique.

Uniqueness of solutions for each block of equations is a straightforward consequence of the continuity of the demand distribution. To establish uniqueness of the equilibrium, we rule out the possibility that the two or more blocks of equations may have solutions that also satisfy the corresponding inequality. This is done in the Appendix A.4.

A notable pattern in the equilibria across the model space is the recursive structure of the order quantities. This pattern greatly 
simplifies the computation of equilibrium order quantities. The order quantity of the player type with highest unit cost is determined based on the demand distribution, the split function and his unit cost, independently of other parameters of the game. The remaining equilibrium quantities are obtained recursively. At each step, substituting for the previously computed equilibrium values, a single equation is solved for a single unknown equilibrium quantity.

The recursive pattern of the equilibrium quantities reflect the fact that the equilibrium is partially dominance-solvable, which in turn is a consequence of the supermodular structure of the game. By Claim 4 above, any quantity strictly less than the stand-alone order quantity is strictly dominated by the stand-alone order quantity for every type. Given this fact and Lemma 5, order quantities strictly greater than the stand-alone order quantity are also dominated by the stand-alone order quantity for the highest cost type $\left(c_{2 H}\right)$. Thus, a two-step reasoning pins the equilibrium behavior of the highest cost type.

The equilibrium described in Theorem 2 can also be understood by following a recursive argument in effective demands. We first explain this for case (i). First, the order quantity for firm 2 when he has the high cost $\left(Q_{2 H}^{*}\right)$ is determined using its stand-alone optimal order quantity. This updates the effective demand for firm 1. Under condition $\left(i_{4}\right)$ this leads to determining the order quantity for firm 1 when he has the low cost $\left(Q_{1 L}^{*}\right)$ using $\left(i_{1}\right)$ and the order quantity for firm 1 when he has the high cost $\left(Q_{1 H}^{*}\right)$ using $\left(i_{2}\right)$. Determining $Q_{1 L}^{*}$ and $Q_{1 H}^{*}$ updates the effective demand for firm 2 and the order quantity for that firm when he has the low cost can be found using $\left(i_{3}\right)$. In case (ii), the order quantity for firm 1 when he has the high cost $\left(Q_{1 H}^{*}\right)$ is found using $\left(i i_{2}\right)$. The order quantity for firm 2 when he has the low cost $\left(Q_{2 L}^{*}\right)$ can then be found using $\left(i i_{3}\right)$. Finally, the order quantity for firm 1 when has the low cost $\left(Q_{1 L}^{*}\right)$ can be determined using $\left(i i_{1}\right)$. In case (iii), the order quantity for firm 2 when he has low cost $\left(Q_{2 L}^{*}\right)$ is also found using his stand-alone optimal order quantity. Determining $Q_{2 L}^{*}$ and $Q_{2 H}^{*}$ updates the effective demand for firm 1 . The order quantities for firm 1 for both types are then determined using ( $\left.i i_{1}\right)$ and $\left(i i_{2}\right)$.

\subsection{Corollaries}

In this sub-section we consider several corollaries of Theorem 2 for special cases of the general model. The first corollary considers a model with ex ante symmetric cost structures without restricting the initial market shares. In the second corollary, we impose a restriction on the initial market share function so that one of the firms has larger initial market share for all demand realizations. Corollary 3 presents the equilibrium for the case with fully symmetric firms where both initial market shares and ex ante cost structures are identical. In Corollary 4, we remove the restrictions on the initial market shares and consider an extreme form of ex ante cost asymmetry: one firm's unit costs are uniformly higher than the other firm's unit costs for all type realizations. Finally, in Corollary 5, we consider a model with symmetric initial market shares and unrestricted ex ante asymmetries in the cost structures. As these corollaries are obtained through straightforward substitutions, we omit the proofs.

Corollary 1. If the two firms are ex ante symmetric with respect to costs, that is, $c_{1 H}=c_{2 H}=c_{H}, c_{1 L}=c_{2 L}=c_{L}$, and $p=q$, then $\left(Q_{1 L}^{*}, Q_{1 H}^{*}, Q_{2 L}^{*}, Q_{2 H}^{*}\right)$ is a Bayesian-Nash equilibrium if and only if

$$
Q_{1 H}^{*}=s\left(\bar{G}^{-1}\left(c_{H}\right)\right), Q_{2 H}^{*}=\hat{s}\left(\bar{G}^{-1}\left(c_{H}\right)\right)
$$

(2) and $Q_{1 L}^{*}$ and $Q_{2 L}^{*}$ satisfy one of the following sets of conditions:

$$
p \bar{G}\left(Q_{1 L}^{*}+\hat{s}\left(\bar{G}^{-1}\left(c_{H}\right)\right)\right)+(1-p) \bar{G}\left(s^{-1}\left(Q_{1 L}^{*}\right)\right)=c_{L}
$$

$$
p \bar{G}\left(Q_{2 L}^{*}+s\left(\bar{G}^{-1}\left(c_{H}\right)\right)\right)+(1-p) \bar{G}\left(Q_{2 L}^{*}+Q_{1 L}^{*}\right)=c_{L}
$$

$$
\hat{s}^{-1}\left(Q_{2 L}^{*}\right) \geq s^{-1}\left(Q_{1 L}^{*}\right)
$$

(ii) $p \bar{G}\left(Q_{1 L}^{*}+\hat{s}\left(\bar{G}^{-1}\left(c_{H}\right)\right)\right)+(1-p) \bar{G}\left(Q_{2 L}^{*}+Q_{1 L}^{*}\right)=c_{L}$

$$
p \bar{G}\left(Q_{2 L}^{*}+s\left(\bar{G}^{-1}\left(c_{H}\right)\right)\right)+(1-p) \bar{G}\left(\hat{s}^{-1}\left(Q_{2 L}^{*}\right)\right)=c_{L}
$$

$s^{-1}\left(Q_{1 L}^{*}\right)>\hat{s}^{-1}\left(Q_{2 L}^{*}\right)$

Further simplification is possible under the assumption that initial market shares of the two firms are uniformly ranked, i.e., one firm's initial market share is higher than the other's for all demand realizations. By relabeling firms if necessary, we can take initial market shares to favor firm 1: $s(d) \geq d / 2$.

Corollary 2. If $c_{1 H}=c_{2 H}=c_{H}, c_{1 L}=c_{2 L}=c_{L}, \quad p=q$ and $s(d)=$ $\hat{s}(d) \geq d / 2$ for all demand levels $d$, then $\left(Q_{1 L}^{*}, Q_{1 H}^{*}, Q_{2 L}^{*}, Q_{2 H}^{*}\right)$ is a Bayesian-Nash equilibrium if and only if

$$
\begin{array}{r}
Q_{1 H}^{*}=s\left(\bar{G}^{-1}\left(c_{H}\right)\right), Q_{2 H}^{*}=\hat{s}\left(\bar{G}^{-1}\left(c_{H}\right)\right) \text { and } \\
Q_{1 L}^{*} \text { and } Q_{2 L}^{*} \text { solve : } \\
p \bar{G}\left(Q_{1 L}^{*}+\hat{s}\left(\bar{G}^{-1}\left(c_{H}\right)\right)\right)+(1-p) \bar{G}\left(s^{-1}\left(Q_{1 L}^{*}\right)\right)=c_{L} \\
p \bar{G}\left(Q_{2 L}^{*}+s\left(\bar{G}^{-1}\left(c_{H}\right)\right)\right)+(1-p) \bar{G}\left(Q_{2 L}^{*}+Q_{1 L}^{*}\right)=c_{L}
\end{array}
$$

When the two firms are fully symmetric in terms of cost structures and initial market shares, we get a fully symmetric equilibrium.

Corollary 3. Assume that the two firms are ex ante symmetric with respect to costs. That is, $c_{1 H}=c_{2 H}=c_{H}, c_{1 L}=c_{2 L}=c_{L}$, and $p=q$. Furthermore, let $s(d)=\hat{s}(d)=d / 2$ for all demand levels $d$. Then $\left(Q_{1 L}^{*}, Q_{1 H}^{*}, Q_{2 L}^{*}, Q_{2 H}^{*}\right)$ is a Bayesian-Nash equilibrium if and only if

$Q_{1 H}^{*}=Q_{2 H}^{*}=Q_{H}^{*}=(1 / 2)\left(\bar{G}^{-1}\left(c_{H}\right)\right)$ and

$Q_{1 L}^{*}=Q_{2 L}^{*}=Q_{L}^{*}$ where $Q_{L}^{*}$ solves

$p \bar{G}\left(Q_{L}^{*}+(1 / 2) \bar{G}^{-1}\left(c_{H}\right)\right)+(1-p) \bar{G}\left(2 Q_{L}^{*}\right)=c_{L}$.

The next corollary looks at the case where one firm has a cost advantage for all cost realizations.

Corollary 4. Assume that $c_{1 L} \leq c_{1 H} \leq c_{2 L} \leq c_{2 H}$. Then $\left(Q_{1 L}^{*}, Q_{1 H}^{*}\right.$, $Q_{2 L}^{*}, Q_{2 H}^{*}$ ) is a Bayesian-Nash equilibrium if and only if

$Q_{2 H}^{*}=\hat{s}\left(\bar{G}^{-1}\left(c_{2 H}\right)\right)$

$Q_{2 L}^{*}=\hat{s}\left(\bar{G}^{-1}\left(c_{2 L}\right)\right)$

$p \bar{G}\left(Q_{1 L}^{*}+\hat{s}\left(\bar{G}^{-1}\left(c_{2 H}\right)\right)\right)+(1-p) \bar{G}\left(Q_{1 L}^{*}+\hat{s}\left(\bar{G}^{-1}\left(c_{2 L}\right)\right)\right)=c_{1 L}$ $p \bar{G}\left(Q_{1 H}^{*}+\hat{s}\left(\bar{G}^{-1}\left(c_{2 H}\right)\right)\right)+(1-p) \bar{G}\left(Q_{1 H}^{*}+\hat{s}\left(\bar{G}^{-1}\left(c_{2 L}\right)\right)\right)=c_{1 H}$.

Corollary 4 uses the fact that $s^{-1}\left(Q_{1 H}^{*}\right) \geq s^{-1}\left(Q_{1 H}^{o}\right) \geq \hat{s}^{-1}\left(Q_{2 L}^{o}\right)=$ $\hat{s}^{-1}\left(Q_{2 L}^{*}\right)$ which satisfies condition $\left(\right.$ iii $\left._{4}\right)$ for case (iii) of Theorem 2 .

As a final corollary, we present the equilibrium order quantities for symmetric initial market shares. In this special case, the equilibrium conditions can be stated explicitly in terms of the exogenous cost parameters, in contrast to the implicit characterization in Theorem 2. For each of the three possible orderings of the unit cost parameters, we have a different set of equilibrium conditions. 
Corollary 5. Assume that $s(d)=\hat{s}(d)=d / 2$. Then $\left(Q_{1 L}^{*}, Q_{1 H}^{*}\right.$, $Q_{2 L}^{*}, Q_{2 H}^{*}$ ) is a Bayesian-Nash equilibrium if and only if

(1) $Q_{2 H}^{*}=(1 / 2) \bar{G}^{-1}\left(c_{2 H}\right)$

(2) $Q_{1 L}^{*}, Q_{1 H}^{*}$ and $Q_{2 L}^{*}$ satisfy one of the following sets of conditions:

(i) If] $c_{2 L} \leq c_{1 L} \leq c_{1 H} \leq c_{2 H}$

$q \bar{G}\left(Q_{1 L}^{*}+(1 / 2) \bar{G}^{-1}\left(c_{2 H}\right)\right)+(1-q) \bar{G}\left(2 Q_{1 L}^{*}\right)=c_{1 L}$

$q \bar{G}\left(Q_{1 H}^{*}+(1 / 2) \bar{G}^{-1}\left(c_{2 H}\right)\right)+(1-q) \bar{G}\left(2 Q_{1 H}^{*}\right)=c_{1 H}$

$p \bar{G}\left(Q_{2 L}^{*}+Q_{1 H}^{*}\right)+(1-p) \bar{G}\left(Q_{2 L}^{*}+Q_{1 L}^{*}\right)=c_{2 L}$

(ii) If $c_{1 L} \leq c_{2 L} \leq c_{1 H} \leq c_{2 H}$

$$
\begin{aligned}
& \left.q \bar{G}\left(Q_{1 L}^{*}+(1 / 2) \bar{G}^{-1}\left(c_{2 H}\right)\right)\right)+(1-q) \bar{G}\left(Q_{2 L}^{*}+Q_{1 L}^{*}\right)=c_{1 L} \\
& q \bar{G}\left(Q_{1 H}^{*}+(1 / 2) \bar{G}^{-1}\left(c_{2 H}\right)\right)+(1-q) \bar{G}\left(2 Q_{1 H}^{*}\right)=c_{1 H} \\
& p \bar{G}\left(Q_{2 L}^{*}+Q_{1 H}^{*}\right)+(1-p) \bar{G}\left(2 Q_{2 L}^{*}\right)=c_{2 L}
\end{aligned}
$$

(iii) If $c_{1 L} \leq c_{1 H} \leq c_{2 L} \leq c_{2 H}$

$$
q \bar{G}\left(Q_{1 L}^{*}+(1 / 2) \bar{G}^{-1}\left(c_{2 H}\right)\right)+(1-q) \bar{G}\left(Q_{1 L}^{*}+(1 / 2) \bar{G}^{-1}\left(c_{2 L}\right)\right)=c_{1 L}
$$

$q \bar{G}\left(Q_{1 H}^{*}+(1 / 2) \bar{G}^{-1}\left(c_{2 H}\right)\right)+(1-q) \bar{G}\left(Q_{1 H}^{*}+(1 / 2) \bar{G}^{-1}\left(c_{2 L}\right)\right)=c_{1 H}$

$Q_{2 L}^{*}=(1 / 2) \bar{G}^{-1}\left(c_{2 L}\right)$

\subsection{Intra-equilibrium comparisons}

As noted in Claim 3 above, equilibrium is monotone: low-cost type of a firm orders a larger quantity than his high-cost type. Without further restrictions on the initial market shares and the level of unit costs, this is about the extent of what can be said regarding intra-equilibrium comparisons. That is, no general ranking of order quantities across firms is possible without imposing further structure on the model. Furthermore, even under normalization an analog of Claim 2 does not hold for equilibrium order quantities. The only possible ranking is the one provided in Lemma 3 that ranks the normalized equilibrium order quantities of the high-cost types of the two firms.

An interesting observation can be made using the characterization in Corollary 4 in the previous section to illustrate a general phenomenon of inter-type externality. Note that the condition in Corollary 4 is only a sufficient condition and the equilibrium characterization there remains valid for a range of unit costs with $c_{2 L}<c_{1 H}<c_{2 H}$ as long as condition (iii $i_{4}$ ) for case (iii) of Theorem 2 is satisfied. In this equilibrium, both types of firm 2 choose an order quantity equal to his stand-alone quantity while it is common knowledge that firm 1 may have larger unit cost. That is, low-cost type firm 2 ignores spillover from the less efficient type of the rival firm. This is due to the fact that high-cost type of firm 1, while less efficient than the low-cost type firm 2, selects a large order quantity expecting spillover demand from the less efficient type of firm 2. The increased order quantity of the firm

\begin{tabular}{|c|c|c|c|c|c|c|c|c|}
\hline Cases & Quantities & Conditions & $c_{1 L}$ & $c_{1 H}$ & $p$ & $c_{2 L}$ & $c_{2 H}$ & $q$ \\
\hline \multirow{5}{*}{ (i) } & $Q_{2 H}^{*}$ & & 0 & 0 & 0 & 0 & - & 0 \\
\hline & $Q_{1 L}^{*}$ & & - & 0 & 0 & 0 & + & + \\
\hline & $Q_{1 H}^{*}$ & & 0 & - & 0 & 0 & + & + \\
\hline & $Q_{2 L}^{*}$ & $\bar{G}\left(Q_{1 L}^{*}+Q_{2 L}^{*}\right)>0$ & + & + & + & - & - & - \\
\hline & $Q_{2 L}^{*}$ & $\bar{G}\left(Q_{1 L}^{*}+Q_{2 L}^{*}\right)=0$ & 0 & + & + & - & - & - \\
\hline \multirow[t]{4}{*}{ (ii) } & $Q_{1 L}^{*}$ & $\bar{G}\left(Q_{1 L}^{*}+Q_{2 L}^{*}\right)>0$ & - & - & - & + & + & + \\
\hline & $Q_{1 L}^{*}$ & $\bar{G}\left(Q_{1 L}^{*}+Q_{2 L}^{*}\right)=0$ & - & 0 & 0 & 0 & + & + \\
\hline & $Q_{1 H}^{*}$ & & 0 & - & 0 & 0 & + & + \\
\hline & $Q_{2 L}^{*}$ & & 0 & + & + & - & - & - \\
\hline \multirow[t]{5}{*}{ (iii) } & $Q_{1 L}^{*}$ & $\bar{G}\left(Q_{1 L}^{*}+Q_{2 L}^{*}\right)>0$ & - & 0 & 0 & + & + & + \\
\hline & $Q_{1 L}^{*}$ & $\bar{G}\left(Q_{1 L}^{*}+Q_{2 L}^{*}\right)=0$ & - & 0 & 0 & 0 & + & + \\
\hline & $Q_{1 H}^{*}$ & $\bar{G}\left(Q_{1 H}^{*}+Q_{2 L}^{*}\right)>0$ & 0 & - & 0 & + & + & + \\
\hline & $Q_{1 H}^{*}$ & $\bar{G}\left(Q_{1 H}^{*}+Q_{2 L}^{*}\right)=0$ & 0 & - & 0 & 0 & + & + \\
\hline & $Q_{2 L}^{*}$ & & 0 & 0 & 0 & - & 0 & 0 \\
\hline
\end{tabular}
$1 H$ forces firm $2 L$ to stick to $Q_{2 L}^{o}$.
Table 1

Comparative statics.

\subsection{Comparative statics}

Comparative static analysis of the equilibrium and payoffs with respect to the exogenous parameters of the model is done in two parts. We first establish general comparative statics results with respect to two exogenous functions in the model, namely, the demand and the market share function. Then we derive explicit comparative static expressions for the scalar parameters.

Theorem 4. Let $D_{A}$ and $D_{B}$ be two positive random variables such that $D_{A}$ dominates $D_{B}$ under first order stochastic dominance. Then, the equilibrium order quantities with industry demand $D_{A}$ are larger than the equilibrium order quantities with industry demand $D_{B}$.

Theorem 5. If $s_{A}(d)>s_{B}(d)$ for all positive real numbers $d$, then the equilibrium order quantities of both types of firm 1 (firm 2) are larger (respectively, smaller) when the split function is $s_{A}$ than the order quantities under $s_{B}$.)

In Table 1, we provide the signs of all first order derivatives of equilibrium order quantities with respect to the exogenous scalar parameters, $c_{1 L}, c_{1 H}, p, c_{2 L}, c_{2 H}$ and $q$. The explicit expressions for the comparative statics derivatives themselves are provided in Appendix A.7. Cases (i), (ii) and (iii) correspond to the cases in Theorem 2.

As expected, the equilibrium order quantities for both players are non-increasing with respect to their own costs and nondecreasing with respect to their rival's costs. In equilibrium, each player orders more as his rival's probability of being high type increases. Conversely, each player orders less as his own probability of being high type increases. This is due to information asymmetry between players and can be explained as follows. Suppose the probability of being high type for firm 1 is increasing. In this case, firm 2 will be ordering more since he will anticipate a higher chance of low order quantity from firm 1 . This will lead firm 1 to expect less spillover from firm 2 and hence order less himself. Whether these monotonicities are strict or not depend on specific cases and conditions as given in Table 1. The only exception to these results is that firm 2's (the firm with larger high cost) equilibrium order quantity when his type is high only depends on its own cost as shown in Theorem 2.

\subsection{An application}

In order to demonstrate the use of the model we developed in this paper, we provide an example in a dual sourcing procurement setting. Dual sourcing or multiple sourcing in general is used extensively in many industries to protect the buyer from supply interruptions and hold-up risk (Burke, Carrillo, \& Vakharia, 2007). 
Table 2

\begin{tabular}{|c|c|c|c|c|c|c|c|c|c|c|}
\hline & $\sigma$ & $s$ & $\hat{c}_{1 L}, \hat{c}_{1 H}$ & $\hat{c}_{2 L}, \hat{c}_{2 H}$ & $\begin{array}{l}Q_{1 L}^{o} \\
Q_{1 L}^{*}\end{array}$ & $\begin{array}{l}Q_{1 H}^{o} \\
Q_{1 H}^{*}\end{array}$ & $\begin{array}{l}Q_{2 L}^{o} \\
Q_{2 L}^{*}\end{array}$ & $\begin{array}{l}Q_{2 H}^{o} \\
Q_{2 H}^{*}\end{array}$ & $\begin{array}{l}\text { ExpInv }^{o} \\
\text { ExpInv }^{*}\end{array}$ & $\begin{array}{l}\text { FillRate }^{o} \\
\text { FillRate }^{*}\end{array}$ \\
\hline \multirow[t]{2}{*}{$A$} & 12,000 & 0.75 & 90,100 & 100,110 & 60,854 & 58,288 & 19,921 & 19,017 & 79,040 & $87.25 \%$ \\
\hline & & & & & 61,537 & 58,463 & 20,167 & 19,017 & 79,592 & $87.73 \%$ \\
\hline \multirow[t]{2}{*}{$B$} & 12,000 & 0.75 & 93,97 & 103,107 & 60,142 & 59,122 & 19,675 & 19,316 & 79,127 & $87.35 \%$ \\
\hline & & & & & 60,693 & 59,333 & 19,675 & 19,316 & 79,508 & $87.68 \%$ \\
\hline \multirow[t]{2}{*}{ C } & 12,000 & 0.75 & 95,95 & 105,105 & 59,643 & 59,643 & 19,500 & 19,500 & 79,144 & $87.36 \%$ \\
\hline & & & & & 60,024 & 60,024 & 19,500 & 19,500 & 79,525 & $87.70 \%$ \\
\hline \multirow[t]{2}{*}{$D$} & 12,000 & 0.50 & 90,100 & 100,110 & 40,569 & 38,859 & 39,841 & 38,035 & 78,652 & $86.90 \%$ \\
\hline & & & & & 42,055 & 39,126 & 40,075 & 38,035 & 79,645 & $87.77 \%$ \\
\hline \multirow[t]{2}{*}{$E$} & 12,000 & 0.25 & 90,100 & 100,110 & 20,285 & 19,429 & 59,762 & 57,052 & 78,264 & $86.54 \%$ \\
\hline & & & & & 22,622 & 19,662 & 59,873 & 57,052 & 79,604 & $87.72 \%$ \\
\hline \multirow[t]{2}{*}{$F$} & 15,000 & 0.75 & 90,100 & 100,110 & 59,380 & 56,173 & 19,338 & 18,209 & 76,550 & $84.06 \%$ \\
\hline & & & & & 60,234 & 56,391 & 19,646 & 18,209 & 77,240 & $84.66 \%$ \\
\hline \multirow[t]{2}{*}{ G } & 18,000 & 0.75 & 90,100 & 100,110 & 57,906 & 54,057 & 18,756 & 17,401 & 74,060 & $80.87 \%$ \\
\hline & & & & & 58,931 & 54,319 & 19,126 & 17,401 & 74,889 & $81.59 \%$ \\
\hline
\end{tabular}

The buyer allocates each supplier it selects a portion of its total procurement of a particular item or a group of items. The selection and allocation decisions can be carried out using a reverse auction (Bichler, Guler, \& Mayer, 2015; Tunca \& Wu, 2009). In some of these procurement settings, the buyer is a manufacturer and uses the procured item as a raw material to manufacture its own good which has an uncertain final demand. In some cases, the buyer may seek to shift the risk of uncertainty in demand to its suppliers and commit each supplier a percentage of its total requirement, rather than in number of units. For example, Hewlett-Packard's procurement commitment from a particular supplier may be a pre-specified percent of the total requirement (a.k.a. total available market) in a given fiscal period (Nagali et al., 2008). In general, it may take time to produce or build up capacity for the item. Therefore, the suppliers may need to make quantity decisions prior to observing demand. This requires each supplier to solve a newsvendor problem to determine its supply quantity. Obviously, if the demand allocated to a supplier exceeds its supply, the buyer can use the other supplier's excess supply, if any, leading to a newsvendor competition among suppliers. Clearly, in this case, the cost information is private to each supplier, making the game an asymmetric information game such as the one we consider in this paper.

For this example, we use data that we have previously collected in Şen, Yaman, Güler, and Körpeoğlu (2014) from procurement bidding events of a large manufacturing company. For one of its components, the company forecasts that the total available market will be 89,000 units. The company allocates $75 \%$ of the total available market to a low cost supplier (supplier 1) which will supply the parts at $w_{1}=\$ 121$ per unit, while the remaining $25 \%$ is allocated to another supplier (supplier 2) which will supply them at $w_{2}=\$ 128$ per unit. It is assumed that the demand is distributed Normally with mean $(\mu)$ equal to the point forecast of 89,000 units. We denote $\hat{c}_{i j}=c_{i j} w_{i}, i \in\{1,2\}$, and $j \in\{L, H\}$. We analyze various scenarios for $\hat{c}_{i j}$ to understand the effect of information asymmetry. We also study the effect of the standard deviation of the Normal distribution $\sigma$ to understand the effect of demand uncertainty for this problem. Note that we have $\mu>4 \sigma$ ensuring that the probability of negative demand is negligibly small. Finally, we consider the effect of the split function, which is described by $s(d)=s d$ in this case, where 100s is the percent of total available market to be procured from supplier 1 .

The results of our analysis for seven instances is given in Table 2. For each instance, the first row of Columns 6-9 report the individual newsvendor order quantities without considering the effect of spillover demand. The second row of Columns 6-9 report the equilibrium order quantities. Columns 10 and 11 report the corresponding expected total inventory from two suppliers and ex- pected fill rates (percent of total demand that can be satisfied by the total inventory created by two suppliers).

In the base instance $A, \sigma=12,000, s=0.75$ and $\left(\hat{c}_{1 L}, \hat{c}_{1 H}, \hat{c}_{2 L}, \hat{c}_{2 H}\right)=(90,100,100,110)$. The spillover competition leads to 552 more units of total inventory in expectation, resulting in approximately $0.5 \%$ increase in the expected fill rate. When $\left(\hat{c}_{1 L}, \hat{c}_{1 H}, \hat{c}_{2 L}, \hat{c}_{2 H}\right)=(93,97,103,107)$ in instance $B$, the asymmetry in cost information decreases. This decreases the total inventory in the Newsvendor competition, whereas the total inventory in the no-competition benchmark is higher than the total inventory in instance $A$. When $\left(\hat{c}_{1 L}, \hat{c}_{1 H}, \hat{c}_{2 L}, \hat{c}_{2 H}\right)=(95,95,105,105)$ in instance $C$, there is no longer information asymmetry in the game. There is a slight increase in total inventory in this case, as the positive effect of cost parameters on order quantities dominates the negative effect of lower strategic interactions due to the elimination of information asymmetry.

In instance $D$, percentage split of supplier 1 (lower cost supplier since $c_{1 L} \leq c_{2 L}$ and $\left.c_{1 H} \leq c_{2 H}\right)$ is reduced to $50 \%$ from $75 \%$ in instance $A$. As expected, this leads to reduced total inventory for the no-interaction model. Interestingly, when the suppliers compete for the spillover demand, this leads to higher total inventory for the buyer. As the percentage allocation of supplier 1 is further reduced to $25 \%$ in instance $E$, the effect of increased cost dominates and the total inventory goes down.

The standard deviation of the demand is first increased to 15,000 in instance $F$ and then to 18,000 in instance $G$. The effect of this on both no competition and competition models is less inventory. However, the effect of spillover competition becomes more pronounced as the uncertainty goes up.

\section{A Special Case: Uniform demand and linear market shares}

In this section, we present the full explicit characterization of the equilibrium and the corresponding payoff functions for uniformly distributed demand and linear market share functions: $D \sim \operatorname{Uniform}(0,1)$, and $s(D)=s D$ and $\hat{s}(D)=(1-s) D$. Under uniform demand and linear market shares, an instance of the model is represented by 7 parameters: $\left(c_{1 L}, c_{1 H}, c_{2 L}, c_{2 H}, p, q, s\right)$.

As shown in Section 4 , while $Q_{2 H}^{*}=(1-s)\left(1-c_{2 H}\right)$, solution to $Q_{1 L}^{*}, Q_{1 H}^{*}$ and $Q_{2 L}^{*}$ (and the corresponding payoffs) requires a detailed analysis.

\subsection{A partition of the parameter space}

Detailed analysis, provided in Appendix A.8, lead to 8 regions in the parameter space. In each of the 8 regions, different equilibrium quantities and payoff functions are valid. In other words, in each of these regions the equilibrium structure (functional form) of at least 
Table 3

Functional forms of endogenous variables by parameter region.

\begin{tabular}{llllllll}
\hline Region & $Q_{1 L}$ & $Q_{1 H}$ & $Q_{2 L}$ & $\pi_{1}\left(c_{1 L}, c_{2 L}\right)$ & $\pi_{1}\left(c_{1 H}, c_{2 L}\right)$ & $\pi_{2}\left(c_{1 L}, c_{2 L}\right)$ & $\pi_{\mathbf{2}}\left(\mathbf{c}_{\mathbf{1 H}}, \mathbf{c}_{\mathbf{2 L}}\right)$ \\
\hline $\mathbf{1}$ & $Q_{1 L}^{\alpha}$ & $Q_{1 H}^{\alpha}$ & $Q_{2 L}^{\alpha}$ & $\pi_{1}^{\alpha}\left(c_{1 L}, c_{2 L}\right)$ & $\pi_{1}^{\alpha}\left(c_{1 H}, c_{2 L}\right)$ & $\pi_{2}^{\alpha}\left(c_{1 L}, c_{2 L}\right)$ & $\pi_{2}^{\alpha}\left(c_{1 H}, c_{2 L}\right)$ \\
$\mathbf{2}$ & $Q_{1 L}^{\beta}$ & $Q_{1 H}^{\alpha}$ & $Q_{2 L}^{\alpha}$ & $\pi_{1}^{\beta}\left(c_{1 L}, c_{2 L}\right)$ & $\pi_{1}^{\alpha}\left(c_{1 H}, c_{2 L}\right)$ & $\pi_{2}^{\beta}\left(c_{1 L}, c_{2 L}\right)$ & $\pi_{2}^{\alpha}\left(c_{1 H}, c_{2 L}\right)$ \\
$\mathbf{3}$ & $Q_{1 L}^{\beta}$ & $Q_{1 H}^{\alpha}$ & $Q_{2 L}^{\beta}$ & $\pi_{1}^{\beta}\left(c_{1 L}, c_{2 L}\right)$ & $\pi_{1}^{\alpha}\left(c_{1 H}, c_{2 L}\right)$ & $\pi_{2}^{\gamma}\left(c_{1 L}, c_{2 L}\right)$ & $\pi_{2}^{\alpha}\left(c_{1 H}, c_{2 L}\right)$ \\
$\mathbf{4}$ & $Q_{1 L}^{\alpha}$ & $Q_{1 H}^{\alpha}$ & $Q_{2 L}^{\gamma}$ & $\pi_{1}^{\gamma}\left(c_{1 L}, c_{2 L}\right)$ & $\pi_{1}^{\alpha}\left(c_{1 H}, c_{2 L}\right)$ & $\pi_{2}^{\delta}\left(c_{1 L}, c_{2 L}\right)$ & $\pi_{2}^{\alpha}\left(c_{1 H}, c_{2 L}\right)$ \\
$\mathbf{5}$ & $Q_{1 L}^{\gamma}$ & $Q_{1 H}^{\alpha}$ & $Q_{2 L}^{\gamma}$ & $\pi_{1}^{\delta}\left(c_{1 L}, c_{2 L}\right)$ & $\pi_{1}^{\alpha}\left(c_{1 H}, c_{2 L}\right)$ & $\pi_{2}^{\delta}\left(c_{1 L}, c_{2 L}\right)$ & $\pi_{2}^{\alpha}\left(c_{1 H}, c_{2 L}\right)$ \\
$\mathbf{6}$ & $Q_{1 L}^{\alpha}$ & $Q_{1 H}^{\beta}$ & $Q_{2 L}^{\delta}$ & $\pi_{1}^{\gamma}\left(c_{1 L}, c_{2 L}\right)$ & $\pi_{1}^{\beta}\left(c_{1 H}, c_{2 L}\right)$ & $\pi_{2}^{\delta}\left(c_{1 L}, c_{2 L}\right)$ & $\pi_{2}^{\beta}\left(c_{1 H}, c_{2 L}\right)$ \\
$\mathbf{7}$ & $Q_{1 L}^{\alpha}$ & $Q_{1 H}^{\gamma}$ & $Q_{2 L}^{\delta}$ & $\pi_{1}^{\gamma}\left(c_{1 L}, c_{2 L}\right)$ & $\pi_{1}^{\gamma}\left(c_{1 H}, c_{2 L}\right)$ & $\pi_{2}^{\delta}\left(c_{1 L}, c_{2 L}\right)$ & $\pi_{2}^{\beta}\left(c_{1 H}, c_{2 L}\right)$ \\
$\mathbf{8}$ & $Q_{1 L}^{\delta}$ & $Q_{1 H}^{\gamma}$ & $Q_{2 L}^{\delta}$ & $\pi_{1}^{\delta}\left(c_{1 L}, c_{2 L}\right)$ & $\pi_{1}^{\gamma}\left(c_{1 H}, c_{2 L}\right)$ & $\pi_{2}^{\delta}\left(c_{1 L}, c_{2 L}\right)$ & $\pi_{2}^{\beta}\left(c_{1 H}, c_{2 L}\right)$ \\
\hline
\end{tabular}

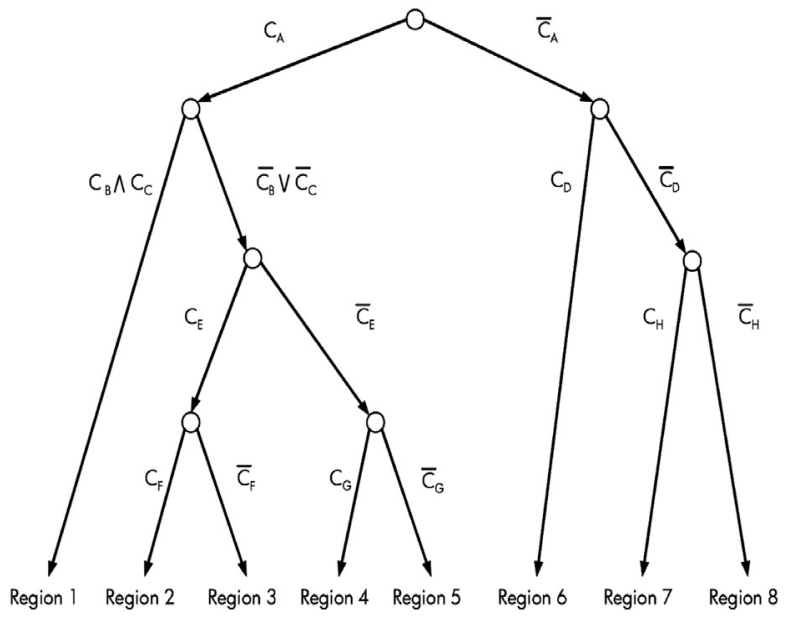

Fig. 1. Conditions characterizing the partition of the parameter space.

one of endogenous variable is different from its from in other regions. The conditions that determine the partition of the parameter space are as follows: Denoting $\hat{p}=s p$ and $\hat{q}=(1-s) q$,

$$
\begin{aligned}
& (1-\hat{q}) c_{2 L}<c_{1 H} \quad-\hat{q} c_{2 H} \quad\left(C_{A}\right) \\
& \begin{array}{cccc}
c_{1 L} & < & \hat{q} c_{2 H} & \left(C_{B}\right)
\end{array} \\
& (1-\hat{q}) c_{2 L}<\hat{p} c_{1 H} \quad-\hat{p} \hat{q} c_{2 H} \quad\left(C_{C}\right) \\
& \hat{q} c_{2 L}<-c_{1 H}+\hat{q} c_{2 H} \quad\left(C_{D}\right) \\
& -(1-\hat{p}) c_{1 L} \quad+(1-\hat{q}) c_{2 L}<\hat{p} c_{1 H} \quad-\hat{q} c_{2 H} \quad\left(C_{E}\right) \\
& \hat{p} c_{1 L} \quad+(1-\hat{q}) c_{2 L}<\hat{p} c_{1 H} \quad\left(C_{F}\right) \\
& (1-\hat{p})(1-\hat{q}) c_{1 L}+\hat{q}(1-\hat{q}) c_{2 L}<\hat{p} \hat{q} c_{1 H}+\hat{q}(1-\hat{p}-\hat{q}) c_{2 H}\left(C_{G}\right) \\
& c_{1 L}+\hat{q} c_{2 L}<\quad \hat{q} c_{2 H} \quad\left(C_{H}\right)
\end{aligned}
$$

The 8 different regions that these equilibrium conditions lead to are given in Figure 1.

\subsection{Equilibrium order quantities}

$Q_{1 L}^{*}, Q_{1 H}^{*}$ and $Q_{2 L}^{*}$ and payoffs $\pi_{1}\left(c_{1 L}, c_{2 L}\right), \pi_{1}\left(c_{1 H}, c_{2 L}\right), \pi_{2}\left(c_{1 L}\right.$, $\left.c_{2 L}\right)$ and $\pi_{2}\left(c_{1 H}, c_{2 L}\right)$ in these regions can be found using the following table:

The equilibrium order quantity for firm 1 when his type is low takes four different functional forms (Table 3):

$$
\begin{aligned}
Q_{1 L}^{\alpha}= & 1-\frac{c_{1 L}}{q}-(1-s)\left(1-c_{2 H}\right), \\
Q_{1 L}^{\beta}= & \frac{\left(1-c_{1 L}-q(1-s)\left(1-c_{2 H}\right)\right)}{(q+(1-q) / s)}, \\
Q_{1 L}^{\gamma}= & 1-c_{1 L}-q(1-s)\left(1-c_{2 H}\right)-\frac{(1-q)\left(1-c_{2 L}\right)}{(p+(1-p) /(1-s))} \\
& +\frac{(1-q) p\left(1-c_{1 H}-q(1-s)\left(1-c_{2 H}\right)\right)}{(q+(1-q) / s)(p+(1-p) /(1-s))}, \\
Q_{1 L}^{\delta}= & 1-c_{1 L}-q(1-s)\left(1-c_{2 H}\right)-(1-q)(1-s)\left(1-c_{2 L}\right) .
\end{aligned}
$$

When firms 1's type is high, his equilibrium order quantity takes three possible forms:

$Q_{1 H}^{\alpha}=\frac{\left(1-c_{1 H}-q(1-s)\left(1-c_{2 H}\right)\right)}{(q+(1-q) / s)}$,

$Q_{1 H}^{\beta}=1-\frac{c_{1 H}}{q}-(1-s)\left(1-c_{2 H}\right)$,

$Q_{1 H}^{\gamma}=1-c_{1 H}-q(1-s)\left(1-c_{2 H}\right)-(1-q)(1-s)\left(1-c_{2 L}\right)$.

Finally, the low type of firm 2 has four different functional forms for his equilibrium order quantity:

$$
\begin{aligned}
Q_{2 L}^{\alpha}= & 1-\frac{c_{2 L}}{p}-\frac{\left(1-c_{1 H}-q(1-s)\left(1-c_{2 H}\right)\right)}{(q+(1-q) / s)}, \\
Q_{2 L}^{\beta}= & 1-c_{2 L}-\frac{p\left(1-c_{1 H}-q(1-s)\left(1-c_{2 H}\right)\right)}{(q+(1-q) / s)} \\
& -\frac{(1-p)\left(1-c_{1 L}-q(1-s)\left(1-c_{2 H}\right)\right)}{(q+(1-q) / s)}, \\
Q_{2 L}^{\gamma}= & \frac{\left(1-c_{2 L}\right)}{(p+(1-p) /(1-s))} \\
& -\frac{p\left(1-c_{1 H}-q(1-s)\left(1-c_{2 H}\right)\right)}{(q+(1-q) / s)(p+(1-p) /(1-s))}, \\
Q_{2 L}^{\delta}= & (1-s)\left(1-c_{2 L}\right) .
\end{aligned}
$$

\subsection{Equilibrium payoffs}

When both firms have low costs, Firm 1's ex post payoff can take four different functional forms:

$$
\begin{aligned}
& \pi_{1}^{\alpha}\left(c_{1 L}, c_{2 L}\right)=\frac{1}{2} s-c_{1 L} Q_{1 L}, \\
& \pi_{1}^{\beta}\left(c_{1 L}, c_{2 L}\right)=Q_{1 L}\left(1-c_{1 L}\right)-\frac{\left(Q_{1 L}\right)^{2}}{2 s}, \\
& \pi_{1}^{\gamma}\left(c_{1 L}, c_{2 L}\right)=\frac{1}{2}+\frac{\left(Q_{2 L}\right)^{2}}{2(1-s)}-Q_{2 L}-c_{1 L} Q_{1 L}, \\
& \pi_{1}^{\delta}\left(c_{1 L}, c_{2 L}\right)=Q_{1 L}\left(1-c_{1 L}\right)+\frac{\left(Q_{2 L}\right)^{2}}{2(1-s)}-\frac{\left(Q_{1 L}+Q_{2 L}\right)^{2}}{2} .
\end{aligned}
$$

Firm 2's payoff, similarly, has four possible functional forms when both firms have low cost:

$$
\begin{aligned}
& \pi_{2}^{\alpha}\left(c_{1 L}, c_{2 L}\right)=\frac{1}{2}(1-s)-c_{2 L} Q_{2 L}, \\
& \pi_{2}^{\beta}\left(c_{1 L}, c_{2 L}\right)=\frac{1}{2}+\frac{\left(Q_{1 L}\right)^{2}}{2 s}-Q_{1 L}-c_{2 L} Q_{2 L}, \\
& \pi_{2}^{\gamma}\left(c_{1 L}, c_{2 L}\right)=Q_{2 L}\left(1-c_{2 L}\right)+\frac{\left(Q_{1 L}\right)^{2}}{2 s}-\frac{\left(Q_{1 L}+Q_{2 L}\right)^{2}}{2}, \\
& \pi_{2}^{\delta}\left(c_{1 L}, c_{2 L}\right)=Q_{2 L}\left(1-c_{2 L}\right)-\frac{\left(Q_{2 L}\right)^{2}}{2(1-s)} .
\end{aligned}
$$

When firms 1 and 2 have low and high costs, respectively, we have three possibilities for the payoff for firm 1's payoff:

$\pi_{1}^{\alpha}\left(c_{1 H}, c_{2 L}\right)=Q_{1 H}\left(1-c_{1 H}\right)-\frac{\left(Q_{1 H}\right)^{2}}{2 s}$, 
Table 4

Comparative statics for uniform demand case.

\begin{tabular}{lllllllllllll}
\hline & $Q_{1 L}^{\alpha}$ & $Q_{1 L}^{\beta}$ & $Q_{1 L}^{\gamma}$ & $Q_{1 L}^{\delta}$ & $Q_{2 L}^{\alpha}$ & $Q_{2 L}^{\beta}$ & $Q_{2 L}^{\gamma}$ & $Q_{2 L}^{\delta}$ & $Q_{1 H}^{\alpha}$ & $Q_{1 H}^{\beta}$ & $Q_{1 H}^{\gamma}$ & $Q_{2 H}$ \\
\hline$c_{1 L}$ & - & - & - & - & 0 & + & 0 & 0 & 0 & 0 & 0 & 0 \\
$c_{1 H}$ & 0 & 0 & - & 0 & + & + & + & 0 & - & - & - & 0 \\
$p$ & 0 & 0 & - & 0 & + & + & + & 0 & 0 & - & - & 0 \\
$c_{2 L}$ & 0 & 0 & + & + & - & - & - & - & 0 & 0 & + & 0 \\
$c_{2 H}$ & + & + & + & + & - & - & - & 0 & + & + & + & - \\
$q$ & + & + & + & + & - & - & - & 0 & + & + & + & 0 \\
$s$ & + & + & + & + & - & - & - & - & + & + & + & - \\
\hline
\end{tabular}

$\pi_{1}^{\beta}\left(c_{1 H}, c_{2 L}\right)=\frac{1}{2}+\frac{\left(Q_{2 L}\right)^{2}}{2(1-s)}-Q_{2 L}-c_{1 H} Q_{1 H}$,

$\pi_{1}^{\gamma}\left(c_{1 H}, c_{2 L}\right)=Q_{1 H}\left(1-c_{1 H}\right)+\frac{\left(Q_{2 L}\right)^{2}}{2(1-s)}-\frac{\left(Q_{1 H}+Q_{2 L}\right)^{2}}{2} ;$

and two possible forms for the payoff for firm 2:

$\pi_{2}^{\alpha}\left(c_{1 H}, c_{2 L}\right)=Q_{2 L}\left(1-c_{2 L}\right)+\frac{\left(Q_{1 H}\right)^{2}}{2 s}-\frac{\left(Q_{1 H}+Q_{2 L}\right)^{2}}{2}$,

$\pi_{2}^{\beta}\left(c_{1 H}, c_{2 L}\right)=Q_{2 L}\left(1-c_{2 L}\right)-\frac{\left(Q_{2 L}\right)^{2}}{2(1-s)}$.

When firm 2 has a high cost, the payoffs of the two players are same in all regions:

$\pi_{1}\left(c_{1 L}, c_{2 H}\right)=Q_{1 L}\left(1-c_{1 L}\right)+\frac{Q_{2 H}^{2}}{2(1-s)}-\frac{\left(Q_{1 L}+Q_{2 H}\right)^{2}}{2}$,

$\pi_{1}\left(c_{1 H}, c_{2 H}\right)=Q_{1 H}\left(1-c_{1 H}\right)+\frac{Q_{2 H}^{2}}{2(1-s)}-\frac{\left(Q_{1 H}+Q_{2 H}\right)^{2}}{2}$,

$\pi_{2}\left(c_{1 L}, c_{2 H}\right)=\pi_{2}\left(c_{1 H}, c_{2 H}\right)=(1-s)\left(1-c_{2 H}\right)^{2} / 2$.

\subsection{Comparative statics}

We present the explicit expressions for comparative static derivatives for the equilibrium order quantities for the uniform demand and linear split case in A.9. Comparative static sign patterns are summarized in Table 4. This is a specific version of Table 1 for the uniform demand and linear split function. Since $s$ characterize the whole split function in this case, we also provide the comparative statics with respect to $s$ in this table.

\section{Concluding remarks}

We studied a model of inventory competition in a newsvendor duopoly under asymmetric cost information. We showed that a pure strategy Bayesian-Nash equilibrium exists under fairly general assumptions. We characterized the equilibrium for the case where the industry demand is allocated between two firms using a deterministic split function and show its uniqueness. We showed that presence of strategic interactions creates incentives to increase order quantities for all firm types except the type that has the highest possible unit cost, who orders the same quantity as he would as a monopolist newsvendor facing scaled version of the market demand. Therefore, competition leads to higher total inventory in the industry. The equilibrium conditions have an interesting recursive structure that enables an easy computation of the equilibrium order quantities. Comparative statics analysis shows that a stochastic increase in market demand or an increase in one firm's initial allocation of the total industry demand lead to higher inventory for that firm. We finally derived a complete characterization of the equilibrium and its comparative statics for the case of uniform demand and linear split rule.

Certain extensions of the current model are relatively straightforward and not likely to change the structure of the equilibrium qualitatively. For instance, allowing more than two levels for the unit costs, will lead to more complicated but qualitatively similar equilibrium characterization in that many of the claims, the recursive structure of the equilibrium order quantities, and, particularly, the behavior of the highest-cost type will remain valid with this extension.

Information asymmetry adds a new dimension to the competitive newsvendor problem. Alternative specifications for the key structural elements of the current model - e.g., the nature of information asymmetry, and the structure of the market and firm demands - span a number of interesting classes of models we intend to explore in the future. Among these are models of newsvendor oligopoly, and models that allow arbitrary statistical dependence in firm demands, and in cost structures.

\section{Acknowledgment}

Kemal Güler's work on final revisions of the research reported in this paper was undertaken during his visit to Bilkent University supported by a fellowship grant from TUBITAK BIDEP 2236 Co-Circulation Fellowship Program Project Number 114C020. He acknowledges with gratitude the financial support of TUBITAK and hospitality of Bilkent University.

\section{Appendix A.}

\section{A1. Proof of Theorem 1}

First, define $\mathcal{Y}_{2}=-\mathcal{Q}_{2}$ so that $\mathcal{Q}_{1} \times \mathcal{Y}_{2}$ is a lattice (This order change is necessary to form a supermodular game). Moreover, let $t_{1}=-c_{1}, t_{2}=c_{2}$ and define effective demand functions as $R_{i}$ : $t_{j} \rightarrow \Re$. Then for

$\pi_{1}\left(Q_{1}, y_{2}, t_{1}, t_{2}\right)=E\left[\min \left\{R_{1}\left(t_{2}\right), Q_{1}\right\}\right]+t_{1} Q_{1}$,

$\pi_{2}\left(Q_{1}, y_{2}, t_{1}, t_{2}\right)=E\left[\min \left\{R_{2}\left(t_{1}\right),-y_{2}\right\}\right]+t_{2} y_{2}$.

The supermodularity and continuity of these functions and the increasing differences in $\left(Q_{1}, y_{2}\right)$ are proved in Lippman and McCardle (1997). The only thing remains is to show that $\pi_{1}$ has increasing differences in $\left(Q_{1}, t_{1}\right)$ and $\pi_{2}$ has increasing differences in $\left(y_{2}, t_{2}\right)$ (Again, $\pi_{i}$ is not directly dependent on the type of firm $j$. Hence, increasing differences for $\left(Q_{1}, t_{2}\right)$ and $\left(y_{2}, t_{1}\right)$ are trivially satisfied.). Let $\varsigma_{1}\left(t_{1}\right)=\pi_{1}\left(Q_{1}^{\prime}, y_{2}, t_{1}, t_{2}\right)-\pi_{1}\left(Q_{1}, y_{2}, t_{1}, t_{2}\right)$ where $Q_{1}^{\prime} \geq Q_{1}$ for given $y_{2}, t_{2}$. Then

$\varsigma_{1}\left(t_{1}\right)=E\left[\min \left\{R_{1}\left(t_{2}\right), Q_{1}^{\prime}\right\}\right]-E\left[\min \left\{R_{1}\left(t_{2}\right), Q_{1}\right\}\right]+t_{1}\left[Q_{1}^{\prime}-Q_{1}\right]$.

Define $t_{1}^{\prime}$ such that $t_{1}^{\prime} \geq t_{1}$. It follows that $\varsigma\left(t_{1}^{\prime}\right)-\varsigma\left(t_{1}\right)=\left[t_{1}^{\prime}-\right.$ $\left.t_{1}\right]\left[Q_{1}^{\prime}-Q_{1}\right] \geq 0$. Thus $\pi_{1}$ has increasing differences in $\left(Q_{1}, t_{1}\right)$. Similarly, $\varsigma_{2}\left(t_{2}\right)=\pi_{2}\left(Q_{1}, y_{2}^{\prime}, t_{1}, t_{2}\right)-\pi_{2}\left(Q_{1}, y_{2}, t_{1}, t_{2}\right)$ where $y_{2}^{\prime} \geq$ $y_{2}$ for given $Q_{1}, t_{1}$. Then

$\varsigma_{2}\left(t_{2}\right)=E\left[\min \left\{R_{2}\left(t_{1}\right),-y_{2}^{\prime}\right\}\right]-E\left[\min \left\{R_{2}\left(t_{1}\right),-y_{2}\right\}\right]+t_{2}\left[y_{2}^{\prime}-y_{2}\right]$. Define $t_{2}^{\prime}$ such that $t_{2}^{\prime} \geq t_{2}$. It follows that $\varsigma\left(t_{2}^{\prime}\right)-\varsigma\left(t_{2}\right)=\left[t_{2}^{\prime}-\right.$ $\left.t_{2}\right]\left[y_{2}^{\prime}-y_{2}\right] \geq 0$. Thus $\pi_{2}$ has increasing differences in $\left(y_{2}, t_{2}\right)$. Since our priors over the types are independent, the condition for priors to be increasing with respect to types is trivially satisfied. The existence of pure strategy Nash equilibrium follows. 
A2. Proof of Claims 1-4 and Lemmas 2-5

Proof of Claim 1. Let $D^{1}=s^{-1}(x)$ and $D^{2}=\hat{s}^{-1}(y)$ and assume $D^{1} \leq D^{2}$. Then,

$$
\begin{aligned}
\min \left\{D^{1}, D^{2}\right\} & =D^{1}=s\left(D^{1}\right)+\hat{s}\left(D^{1}\right) \leq s\left(D^{1}\right)+\hat{s}\left(D^{2}\right) \\
& \leq s\left(D^{2}\right)+\hat{s}\left(D^{2}\right)=D^{2}=\max \left\{D^{1}, D^{2}\right\} .
\end{aligned}
$$

Since $s\left(D^{1}\right)=x$ and $\hat{s}\left(D^{2}\right)=y$, we obtain the desired result.

Proof of Claim 2. $\operatorname{Pr}\left(D_{1} \geq Q_{1 H}^{o}\right)=\operatorname{Pr}\left(D \geq s^{-1}\left(Q_{1 H}^{o}\right)\right)=c_{1 H} \leq c_{2 H}=$ $\operatorname{Pr}\left(D \geq \hat{s}^{-1}\left(Q_{2 H}^{o}\right)\right)$.

Hence, $s^{-1}\left(Q_{1 H}^{o}\right) \geq \hat{s}^{-1}\left(Q_{2 H}^{o}\right)$.

Proof of Claim 3. (i) (1) evaluated at $Q_{1 L}=Q_{1 H}^{*}$ is positive.

(ii) Similar argument with (i).

Proof of Claim 4. We will only show (i). Other cases are established similarly. Evaluating the left hand side of (1) at $Q_{1 L}=Q_{1 L}^{o}$ gives:

$$
\begin{aligned}
& q \operatorname{Pr}\left(D_{1}+\left(D_{2}-Q_{2 H}\right)^{+} \geq Q_{1 L}^{o}\right)+(1-q) \\
& \quad \operatorname{Pr}\left(D_{1}+\left(D_{2}-Q_{2 L}\right)^{+} \geq Q_{1 L}^{o}\right)-c_{1 L} \\
& \quad \geq q \operatorname{Pr}\left(D_{1} \geq Q_{1 L}^{o}\right)+(1-q) \operatorname{Pr}\left(D_{1} \geq Q_{1 L}^{o}\right) \\
& \quad-c_{1 L}=\operatorname{Pr}\left(D_{1} \geq Q_{1 L}^{o}\right)-c_{1 L}=0
\end{aligned}
$$

Thus, $Q_{1 L}^{*} \geq Q_{1 L}^{o}$.

Proof of Lemma 2. Assume that $s^{-1}\left(Q_{1 H}^{*}\right)>\hat{s}^{-1}\left(Q_{2 H}^{*}\right)$. First note that,

$$
\begin{aligned}
& \operatorname{Pr}\left(D_{2}+\left(D_{1}-Q_{1}\right)^{+} \geq Q_{2}\right)=\operatorname{Pr}\left(D \geq s^{-1}\left(Q_{1}\right),\right. \\
& \left.D \geq Q_{1}+Q_{2}\right)+\operatorname{Pr}\left(D \leq s^{-1}\left(Q_{1}\right), D \geq \hat{s}^{-1}\left(Q_{2}\right)\right) .
\end{aligned}
$$

By substituting this in (4) we obtain:

$$
\begin{aligned}
& \operatorname{pr}\left(D \geq s^{-1}\left(Q_{1 H}^{*}\right), D \geq Q_{2 H}^{*}+Q_{1 H}^{*}\right)+p \operatorname{Pr}\left(D \leq s^{-1}\left(Q_{1 H}^{*}\right),\right. \\
& \left.\quad D \geq \hat{s}^{-1}\left(Q_{2 H}^{*}\right)\right) \\
& \quad+(1-p) \operatorname{Pr}\left(D \geq s^{-1}\left(Q_{1 L}^{*}\right), D \geq Q_{2 H}^{*}+Q_{1 L}^{*}\right) \\
& \quad+(1-p) \operatorname{Pr}\left(D \leq s^{-1}\left(Q_{1 L}^{*}\right), D \geq \hat{s}^{-1}\left(Q_{2 H}^{*}\right)\right)-c_{2 H}=0
\end{aligned}
$$

Since $s^{-1}\left(Q_{1 H}^{*}\right)>\hat{s}^{-1}\left(Q_{2 H}^{*}\right), s^{-1}\left(Q_{1 L}^{*}\right)>\hat{s}^{-1}\left(Q_{2 H}^{*}\right)$ by Claim 3 . By Claim $1, \operatorname{Pr}\left(D \geq s^{-1}\left(Q_{1 H}^{*}\right), D \geq Q_{2 H}^{*}+Q_{1 H}^{*}\right)=\operatorname{Pr}\left(D \geq s^{-1}\left(Q_{1 H}^{*}\right)\right.$. In addition, $\operatorname{Pr}\left(D \geq s^{-1}\left(Q_{1 H}^{*}\right)\right)+\operatorname{Pr}\left(\hat{s}^{-1}\left(Q_{2 H}^{*}\right) \leq D \leq s^{-1}\left(Q_{1 H}^{*}\right)\right)=$ $\operatorname{Pr}\left(D \geq \hat{s}^{-1}\left(Q_{2 H}^{*}\right)\right)$. Therefore,

$$
\begin{aligned}
& \operatorname{pPr}\left(D \geq \hat{s}^{-1}\left(Q_{2 H}^{*}\right)\right)+(1-p) \operatorname{Pr}\left(D \geq \hat{s}^{-1}\left(Q_{2 H}^{*}\right)\right) \\
& -c_{2 H}=\operatorname{Pr}\left(D \geq \hat{s}^{-1}\left(Q_{2 H}^{*}\right)\right)-c_{2 H}=0 .
\end{aligned}
$$

Thus, $Q_{2 H}^{*}=Q_{2 H}^{o}$. Using $s^{-1}\left(Q_{1 H}^{*}\right) \leq \hat{s}^{-1}\left(Q_{2 H}^{*}\right)<\hat{s}^{-1}\left(Q_{2 L}^{*}\right)$ in (2) in a similar fashion gives the result $Q_{1 H}^{*}=Q_{1 H}^{o}$.

Proof of Lemma 3. Assume to the contrary that for $c_{1 H} \leq c_{2 H}$, $s^{-1}\left(Q_{1 H}^{*}\right)<\hat{s}^{-1}\left(Q_{2 H}^{*}\right)$. Then, by Lemma $1, Q_{1 H}^{*}=Q_{1 H}^{o}$. By Claims 2 and 3 , we get $s^{-1}\left(Q_{1 H}^{*}\right) \geq s^{-1}\left(Q_{1 H}^{o}\right) \geq \hat{s}^{-1}\left(Q_{2 H}^{o}\right)$ and

$$
\begin{aligned}
& \operatorname{Pr}\left(D \geq Q_{2 H}^{*}+Q_{1 H}^{*}\right) \leq \operatorname{Pr}\left(D \geq Q_{2 H}^{o}+Q_{1 H}^{o}\right)<\operatorname{Pr}\left(D \geq Q_{2 H}^{o}\right. \\
& \left.\quad+\hat{s}\left(s^{-1}\left(Q_{2 H}^{o}\right)\right)\right)=\operatorname{Pr}\left(\hat{s}(D) \geq Q_{2 H}^{o}\right)=c_{2 H} . \quad(*)
\end{aligned}
$$

Now, we have either $s^{-1}\left(Q_{1 L}^{*}\right)>\hat{s}^{-1}\left(Q_{2 H}^{*}\right)$ or $s^{-1}\left(Q_{1 L}^{*}\right) \leq$ $\hat{S}^{-1}\left(Q_{2 H}^{*}\right)$. In the first case equilibrium condition (4) simplifies to:

$$
\begin{aligned}
& c_{2 H}=p \operatorname{Pr}\left(D \geq Q_{2 H}^{*}+Q_{1 H}^{*}\right)+(1-p) \operatorname{Pr}\left(\hat{s}(D) \geq Q_{2 H}^{*}\right) \\
& \quad \leq p \operatorname{Pr}\left(D \geq Q_{2 H}^{*}+Q_{1 H}^{*}\right)+(1-p) c_{2 H},
\end{aligned}
$$

since $\operatorname{Pr}\left(\hat{s}(D) \geq Q_{2 H}^{*}\right) \leq \operatorname{Pr}\left(\hat{s}(D) \geq Q_{2 H}^{o}\right)$ by Claim 4 and $\operatorname{Pr}(\hat{s}(D) \geq$ $\left.Q_{2 H}^{o}\right)=c_{2 H}$ by definition. This leads to

$c_{2 H} \leq p \operatorname{Pr}\left(D \geq Q_{2 H}^{*}+Q_{1 H}^{*}\right)+(1-p) c_{2 H} \leq \operatorname{Pr}\left(D \geq Q_{2 H}^{*}+Q_{1 H}^{*}\right)$,

which is a contradiction to $\left(^{*}\right)$.
For the second case, the equilibrium condition (4) simplifies to:

$$
\begin{aligned}
& c_{2 H}=p \operatorname{Pr}\left(D \geq Q_{2 H}^{*}+Q_{1 H}^{*}\right)+(1-p) \operatorname{Pr}\left(D \geq Q_{2 H}^{*}+Q_{1 L}^{*}\right) \\
& \quad<\operatorname{Pr}\left(D \geq Q_{2 H}^{*}+Q_{1 H}^{*}\right),
\end{aligned}
$$

since $Q_{1 L}^{*}>Q_{1 H}^{*}$ by Claim 3. Again this contradicts $\left({ }^{*}\right)$.

Proof of Lemma 4. By Lemma 2, $c_{1 H} \leq c_{2 H}$ implies $s^{-1}\left(Q_{1 H}^{*}\right) \geq$ $\hat{s}^{-1}\left(Q_{2 H}^{*}\right)$. Using this condition in Lemma 1 yields the desired result.

Proof of Lemma 5. First note that $Q_{i L}^{o}$ and $Q_{i H}^{o}$ are stand-alone order levels for firms $i=1,2$. It is important to notice that each firm will at least play his stand-alone order quantity in the equilibrium. Now, define $Q_{2 H}^{1}$ as the order level of high type of firm 2 when firm 1 plays his stand-alone quantities for both his types in the equilibrium i.e.,

$$
\begin{aligned}
& p \operatorname{Pr}\left(\hat{s}(D)+\left(s(D)-Q_{1 H}^{o}\right)^{+} \geq Q_{2 H}^{1}\right)+(1-p) \operatorname{Pr}(\hat{s}(D) \\
& \left.\quad+\left(s(D)-Q_{1 L}^{o}\right)^{+} \geq Q_{2 H}^{1}\right)-c_{2 H}=0 .
\end{aligned}
$$

and $Q_{2 H}^{1} \geq Q_{2 H}^{o}$ since firm 2 will play at least his stand-alone order level. Rewriting the equilibrium condition gives,

$$
\begin{aligned}
& p \operatorname{Pr}\left(D \geq s^{-1}\left(Q_{1}^{o}\right), D \geq Q_{1 H}^{o}+Q_{2 H}^{1}\right) \\
& \quad+p \operatorname{Pr}\left(D \leq s^{-1}\left(Q_{1 H}^{o}\right), D \geq \hat{s}^{-1}\left(Q_{2 H}^{1}\right)\right) \\
& \quad+(1-p) \operatorname{Pr}\left(D \geq s^{-1}\left(Q_{1 L}^{o}\right), D \geq Q_{1 L}^{o}+Q_{2 H}^{1}\right) \\
& \quad+(1-p) \operatorname{Pr}\left(D \leq s^{-1}\left(Q_{1 L}^{o}\right), D \geq \hat{s}^{-1}\left(Q_{2 H}^{1}\right)\right)-c_{2 H}=0 .
\end{aligned}
$$

For this equilibrium condition, we have three possibilities: $\hat{s}^{-1}\left(Q_{2 H}^{1}\right) \leq s^{-1}\left(Q_{1 H}^{o}\right), \quad s^{-1}\left(Q_{1 H}^{o}\right)<\hat{s}^{-1}\left(Q_{2 H}^{1}\right) \leq s^{-1}\left(Q_{1 L}^{o}\right) \quad$ and $s^{-1}\left(Q_{1 L}^{o}\right)<\hat{s}^{-1}\left(Q_{2 H}^{1}\right)$. First assume $\hat{s}^{-1}\left(Q_{2 H}^{1}\right) \leq s^{-1}\left(Q_{1 H}^{o}\right)$, then the equilibrium condition becomes:

$$
\begin{aligned}
& \operatorname{pPr}\left(D \geq \hat{s}^{-1}\left(Q_{2 H}^{1}\right)\right)+(1-p) \operatorname{Pr}\left(D \geq \hat{s}^{-1}\left(Q_{2 H}^{1}\right)\right)-c_{2 H} \\
& \quad=\operatorname{Pr}\left(D \geq \hat{s}^{-1}\left(Q_{2 H}^{1}\right)\right)-c_{2 H}=0 .
\end{aligned}
$$

Thus, $Q_{2 H}^{1}=Q_{2 H}^{o}$. Now, we assume that $s^{-1}\left(Q_{1 H}^{o}\right)<\hat{s}^{-1}\left(Q_{2 H}^{1}\right)<$ $s^{-1}\left(Q_{1 L}^{o}\right)$. Moreover, if we use the fact that $s^{-1}\left(Q_{1 H}^{o}\right)<Q_{1 H}^{o}+Q_{2 H}^{1}$ (by Claim 1), the condition becomes

$$
\begin{aligned}
0 & =p \operatorname{Pr}\left(D \geq Q_{1 H}^{o}+Q_{2 H}^{1}\right)+(1-p) \operatorname{Pr}\left(D \geq \hat{s}^{-1}\left(Q_{2 H}^{1}\right)\right)-c_{2 H} \\
& <p \operatorname{Pr}\left(D \geq s^{-1}\left(Q_{1 H}^{o}\right)\right)+(1-p) \operatorname{Pr}\left(D \geq s^{-1}\left(Q_{1 H}^{o}\right)\right)-c_{2 H} \\
& =\operatorname{Pr}\left(D \geq s^{-1}\left(Q_{1 H}^{o}\right)\right)-c_{2 H}=c_{1 H}-c_{2 H}
\end{aligned}
$$

Thus, $c_{1 H}>c_{2 H}$ which is a contradiction to our assumption that $c_{1 H} \leq c_{2 H}$. A similar proof can be obtained for $s^{-1}\left(Q_{1 L}^{o}\right) \leq \hat{s}^{-1}\left(Q_{2 H}^{1}\right)$. Hence, $Q_{2 H}^{1}=Q_{2 H}^{o}$ which implies that any order quantity of high type of firm 2 satisfies $Q_{2 H} \leq Q_{2 H}^{o}$. Combining this with the fact that $Q_{2 H} \geq Q_{2 H}^{o}$, we obtain $Q_{2 H}=Q_{2 H}^{o}$.

\section{A3. Proof of Theorem 2}

Under an increasing and deterministic split function, we know that there is a unique Bayesian-Nash equilibrium and using Lemma 3, our unique equilibrium conditions take the form:

$$
\begin{aligned}
& q \operatorname{Pr}\left(D \geq Q_{1 L}^{*}+\hat{s}\left(\bar{G}^{-1}\left(c_{2 H}\right)\right)\right) \\
& \quad+(1-q) \operatorname{Pr}\left(D_{1}+\left(D_{2}-Q_{2 L}^{*}\right)^{+} \geq Q_{1 L}^{*}\right)=c_{1 L}, \\
& q \operatorname{Pr}\left(D \geq Q_{1 H}^{*}+\hat{s}\left(\bar{G}^{-1}\left(c_{2 H}\right)\right)\right) \\
& \quad+(1-q) \operatorname{Pr}\left(D_{1}+\left(D_{2}-Q_{2 L}^{*}\right)^{+} \geq Q_{1 H}^{*}\right)=c_{1 H}, \\
& \operatorname{PPr}\left(D_{2}+\left(D_{1}-Q_{1 H}^{*}\right)^{+} \geq Q_{2 L}^{*}\right) \\
& \quad+(1-p) \operatorname{Pr}\left(D_{2}+\left(D_{1}-Q_{1 L}^{*}\right)^{+} \geq Q_{2 L}^{*}\right)=c_{2 L}, \\
& Q_{2 H}^{*}=\hat{s}\left(\bar{G}^{-1}\left(c_{2 H}\right)\right) .
\end{aligned}
$$

Now, if we use $D_{1}=s(D)$ and $D_{2}=\hat{s}(D)$ and use the fact that,

$$
\begin{aligned}
& \operatorname{Pr}\left(D_{1}+\left(D_{2}-Q_{2}\right)^{+} \geq Q_{1}\right)=\operatorname{Pr}\left(D \geq \hat{s}^{-1}\left(Q_{2}\right), D \geq Q_{2}+Q_{1}\right) \\
& \quad+\operatorname{Pr}\left(D \leq \hat{s}^{-1}\left(Q_{2}\right), D \geq s^{-1}\left(Q_{1}\right)\right),
\end{aligned}
$$




$$
\begin{aligned}
& \operatorname{Pr}\left(D_{2}+\left(D_{1}-Q_{1}\right)^{+} \geq Q_{2}\right)=\operatorname{Pr}\left(D \geq s^{-1}\left(Q_{1}\right), D \geq Q_{1}+Q_{2}\right) \\
& \quad+\operatorname{Pr}\left(D \leq s^{-1}\left(Q_{1}\right), D \geq \hat{s}^{-1}\left(Q_{2}\right)\right),
\end{aligned}
$$

which can be obtained using a simple conditional probability argument, equilibrium conditions will become:

$$
\begin{aligned}
& q \operatorname{Pr}\left(D \geq Q_{1 L}^{*}+\hat{s}\left(\bar{G}^{-1}\left(c_{2 H}\right)\right)\right) \\
& +(1-q) \operatorname{Pr}\left(D \geq \hat{s}^{-1}\left(Q_{2 L}^{*}\right), D \geq Q_{2 L}^{*}+Q_{1 L}^{*}\right) \\
& +(1-q) \operatorname{Pr}\left(D \leq \hat{s}^{-1}\left(Q_{2 L}^{*}\right), D \geq s^{-1}\left(Q_{1 L}^{*}\right)\right)=c_{1 L},
\end{aligned}
$$

$q \operatorname{Pr}\left(D \geq Q_{1 H}^{*}+\hat{s}\left(\bar{G}^{-1}\left(c_{2 H}\right)\right)\right)$

$$
\begin{aligned}
& +(1-q) \operatorname{Pr}\left(D \geq \hat{s}^{-1}\left(Q_{2 L}^{*}\right), D \geq Q_{2 L}^{*}+Q_{1 H}^{*}\right) \\
& +(1-q) \operatorname{Pr}\left(D \leq \hat{s}^{-1}\left(Q_{2 L}^{*}\right), D \geq s^{-1}\left(Q_{1 H}^{*}\right)\right)=c_{1 H},
\end{aligned}
$$

$$
\begin{aligned}
& \operatorname{pr}\left(D \geq s^{-1}\left(Q_{1 H}^{*}\right), D \geq Q_{2 L}^{*}+Q_{1 H}^{*}\right)+p \operatorname{Pr}\left(D \leq s^{-1}\left(Q_{1 H}^{*}\right)\right. \\
& \left.\quad D \geq \hat{s}^{-1}\left(Q_{2 L}^{*}\right)\right) \\
& \quad+(1-p) \operatorname{Pr}\left(D \geq s^{-1}\left(Q_{1 L}^{*}\right), D \geq Q_{2 L}^{*}+Q_{1 L}^{*}\right) \\
& \quad+(1-p) \operatorname{Pr}\left(D \leq s^{-1}\left(Q_{1 L}^{*}\right), D \geq \hat{s}^{-1}\left(Q_{2 L}^{*}\right)\right)=c_{2 L},
\end{aligned}
$$

$Q_{2 H}^{*}=\hat{s}\left(\bar{G}^{-1}\left(c_{2 H}\right)\right)$.

The proof of part 1 follows since $Q_{2 H}^{*}=\hat{s}\left(\bar{G}^{-1}\left(c_{2 H}\right)\right)$ is obviously an equilibrium condition.

Part 2 has three separate subsets. To prove $(i)$, let $\hat{s}^{-1}\left(Q_{2 L}^{*}\right) \geq$ $s^{-1}\left(Q_{1 L}^{*}\right)$. $\left(A_{1}\right)$ becomes $\left(i_{1}\right)$ :

$$
\begin{aligned}
q \bar{G} & \left(Q_{1 L}^{*}+\hat{s}\left(\bar{G}^{-1}\left(c_{2 H}\right)\right)\right)+(1-q) \operatorname{Pr}\left(D \geq \hat{s}^{-1}\left(Q_{2 L}^{*}\right),\right. \\
& \left.D \geq Q_{2 L}^{*}+Q_{1 L}^{*}\right)+(1-q) \operatorname{Pr}\left(D \leq \hat{s}^{-1}\left(Q_{2 L}^{*}\right), D \geq s^{-1}\left(Q_{1 L}^{*}\right)\right) \\
& =q \bar{G}\left(Q_{1 L}^{*}+\hat{s}\left(\bar{G}^{-1}\left(c_{2 H}\right)\right)\right)+(1-q) \operatorname{Pr}\left(D \geq s^{-1}\left(Q_{1 L}^{*}\right)\right) \\
& =q \bar{G}\left(Q_{1 L}^{*}+\hat{s}\left(\bar{G}^{-1}\left(c_{2 H}\right)\right)\right)+(1-q) \bar{G}^{-1}\left(s^{-1}\left(Q_{1 L}^{*}\right)\right)=c_{1 L} .
\end{aligned}
$$

Similarly, using the fact that $\hat{s}^{-1}\left(Q_{2 L}^{*}\right) \geq s^{-1}\left(Q_{1 L}^{*}\right)$ implies $\hat{s}^{-1}\left(Q_{2 L}^{*}\right) \geq s^{-1}\left(Q_{1 H}^{*}\right),\left(A_{2}\right)$ becomes $\left(i_{2}\right)$ :

$$
\begin{aligned}
q \bar{G} & \left(Q_{1 H}^{*}+\hat{s}\left(\bar{G}^{-1}\left(c_{2 H}\right)\right)\right)+(1-q) \operatorname{Pr}\left(D \geq \hat{s}^{-1}\left(Q_{2 L}^{*}\right),\right. \\
& \left.D \geq Q_{2 L}^{*}+Q_{1 H}^{*}\right)+(1-q) \operatorname{Pr}\left(D \leq \hat{s}^{-1}\left(Q_{2 L}^{*}\right), D \geq s^{-1}\left(Q_{1 H}^{*}\right)\right) \\
& =q \bar{G}\left(Q_{1 L}^{*}+\hat{s}\left(\bar{G}^{-1}\left(c_{2 H}\right)\right)\right)+(1-q) \operatorname{Pr}\left(D \geq s^{-1}\left(Q_{1 H}^{*}\right)\right) \\
& =q \bar{G}\left(Q_{1 H}^{*}+\hat{s}\left(\bar{G}^{-1}\left(c_{2 H}\right)\right)\right)+(1-q) \bar{G}^{-1}\left(s^{-1}\left(Q_{1 H}^{*}\right)\right)=c_{1 H} .
\end{aligned}
$$

And combining two inequalities, $\left(A_{3}\right)$ becomes $\left(i_{3}\right)$ :

$$
\begin{aligned}
p & \operatorname{Pr}\left(D \geq s^{-1}\left(Q_{1 H}^{*}\right), D \geq Q_{2 L}^{*}+Q_{1 H}^{*}\right) \\
& +p \operatorname{Pr}\left(D \leq s^{-1}\left(Q_{1 H}^{*}\right), D \geq \hat{s}^{-1}\left(Q_{2 L}^{*}\right)\right) \\
& +(1-p) \operatorname{Pr}\left(D \geq s^{-1}\left(Q_{1 L}^{*}\right), D \geq Q_{2 L}^{*}+Q_{1 L}^{*}\right) \\
& +(1-p) \operatorname{Pr}\left(D \leq s^{-1}\left(Q_{1 L}^{*}\right), D \geq \hat{s}^{-1}\left(Q_{2 L}^{*}\right)\right) \\
= & p \operatorname{Pr}\left(D \geq Q_{2 L}^{*}+Q_{1 H}^{*}\right)+(1-p) \operatorname{Pr}\left(D \geq Q_{2 L}^{*}+Q_{1 L}^{*}\right) \\
= & p \bar{G}^{-1}\left(D \geq Q_{2 L}^{*}+Q_{1 H}^{*}\right)+(1-p) \bar{G}^{-1}\left(D \geq Q_{2 L}^{*}+Q_{1 L}^{*}\right)=c_{2 L} .
\end{aligned}
$$

The proof for (ii) and (iii) follows similarly under $s^{-1}\left(Q_{1 L}^{*}\right)>$ $\hat{s}^{-1}\left(Q_{2 L}^{*}\right) \geq s^{-1}\left(Q_{1 H}^{*}\right)$ and $s^{-1}\left(Q_{1 H}^{*}\right)>\hat{s}^{-1}\left(Q_{2 L}^{*}\right)$.

\section{A4. Proof of Theorem 3}

First, since the demand has a continuous distribution, the inverse of distribution function $G$ and $\bar{G}$ are well-defined. Only one of the (i), (ii) or (iii) given in Theorem 2 can be satisfied since a vector of order quantities satisfying one of the inequality conditions $\left(i_{4}\right),\left(i i_{4}\right)$ or $\left(i i_{4}\right)$ cannot satisfy others.
Take the region $(i)$. There can be only one $Q_{1 L}^{*}$ satisfying condition $\left(i_{1}\right)$ which is:

$q \bar{G}\left(Q_{1 L}^{*}+\hat{s}\left(\bar{G}^{-1}\left(c_{2 H}\right)\right)\right)+(1-q) \bar{G}\left(s^{-1}\left(Q_{1 L}^{*}\right)\right)=c_{1 L}$,

since $s^{-1}, \hat{s}^{-1}$ and $\bar{G}^{-1}$ gives unique results and it does not depend on any other variables. Similarly, only one $Q_{1 H}^{*}$ satisfies $\left(i_{2}\right)$ :

$q \bar{G}\left(Q_{1 H}^{*}+\hat{s}\left(\bar{G}^{-1}\left(c_{2 H}\right)\right)\right)+(1-q) \bar{G}\left(s^{-1}\left(Q_{1 H}^{*}\right)\right)=c_{1 H}$.

Since both $Q_{1 L}^{*}$ and $Q_{1 H}^{*}$ are unique, $\left(i_{3}\right)$ i.e.,

$p \bar{G}\left(Q_{2 L}^{*}+Q_{1 H}^{*}\right)+(1-p) \bar{G}\left(Q_{2 L}^{*}+Q_{1 L}^{*}\right)=c_{2 L}$,

also gives a unique $Q_{2 L}^{*}$. Thus, the set of order quantities satisfying region $(i)$ is unique.

Similar arguments are valid for regions (ii) and (iii). The argument so far does not rule out multiple equilibria each of which is the unique solution of one of three blocks of equalities. Finally, we need to show that only one of that three cases can arise.

Assume to the contrary that case $(i)$ and (ii) gives different solutions. Now, let $\left(Q_{1 L}^{*}, Q_{1 H}^{*}, Q_{2 L}^{*}, Q_{2 H}^{*}\right)$ and $\left(\hat{Q}_{1 L}, \hat{Q}_{1 H}, \hat{Q}_{2 L}, \hat{Q}_{2 H}\right)$ be the solutions of cases $(i)$ and (ii) respectively. First notice that $Q_{1 H}^{*}=\hat{Q}_{1 H}=Q_{1 H}$ and $Q_{2 H}^{*}=\hat{Q}_{2 H}=Q_{2 H}$ since they require the same conditions. However, low type quantities should satisfy:

$$
\begin{aligned}
& q \bar{G}\left(Q_{1 L}^{*}+Q_{2 H}\right)+(1-q) \bar{G}\left(s^{-1}\left(Q_{1 L}^{*}\right)\right) \\
& \quad=q \bar{G}\left(\hat{Q}_{1 L}+Q_{2 H}\right)+(1-q) \bar{G}\left(\hat{Q}_{2 L}+\hat{Q}_{1 L}\right) \\
& \quad p \bar{G}\left(Q_{2 L}^{*}+Q_{1 H}\right)+(1-p) \bar{G}\left(Q_{2 L}^{*}+Q_{1 L}^{*}\right) \\
& \quad=p \bar{G}\left(\hat{Q}_{2 L}+Q_{1 H}\right)+(1-p) \bar{G}\left(\hat{s}^{-1}\left(\hat{Q}_{2 L}\right)\right) \\
& \quad \hat{s}^{-1}\left(Q_{2 L}^{*}\right) \geq Q_{1 L}^{*}+Q_{2 L}^{*} \geq s^{-1}\left(Q_{1 L}^{*}\right) \\
& \quad \hat{s}^{-1}\left(\hat{Q}_{2 L}\right)<\hat{Q}_{1 L}+\hat{Q}_{2 L}<s^{-1}\left(\hat{Q}_{1 L}\right)
\end{aligned}
$$

where inequalities come from Claim 4 . Thus, we have

$$
\begin{aligned}
& q \bar{G}\left(Q_{1 L}^{*}+Q_{2 H}\right)+(1-q) \bar{G}\left(s^{-1}\left(Q_{1 L}^{*}\right)\right) \\
& \quad>q \bar{G}\left(\hat{Q}_{1 L}+Q_{2 H}\right)+(1-q) \bar{G}\left(s^{-1}\left(\hat{Q}_{1 L}\right)\right) \\
& \quad p \bar{G}\left(Q_{2 L}^{*}+Q_{1 H}\right)+(1-p) \bar{G}\left(\hat{s}^{-1}\left(Q_{2 L}^{*}\right)\right) \\
& \quad<p \bar{G}\left(\hat{Q}_{2 L}+Q_{1 H}\right)+(1-p) \bar{G}\left(\hat{s}^{-1}\left(\hat{Q}_{2 L}\right)\right)
\end{aligned}
$$

which implies $Q_{1 L}^{*}<\hat{Q}_{1 L}$ and $Q_{2 L}^{*}>\hat{Q}_{2 L}$ (Remember that $\bar{G}$ is a decreasing function.). If we use this in equilibrium conditions,

$\bar{G}\left(s^{-1}\left(Q_{1 L}^{*}\right)\right)<\bar{G}\left(\hat{Q}_{2 L}+\hat{Q}_{1 L}\right)$

$\bar{G}\left(Q_{2 L}^{*}+Q_{1 L}^{*}\right)>\bar{G}\left(\hat{s}^{-1}\left(\hat{Q}_{2 L}\right)\right)$

meaning that both $Q_{1 L}^{*}+Q_{2 L}^{*}>s^{-1}\left(Q_{1 L}^{*}\right)>\hat{Q}_{2 L}+\hat{Q}_{1 L}$ and $\hat{Q}_{2 L}+$ $\hat{Q}_{1 L}>\hat{s}^{-1}\left(\hat{Q}_{2 L}\right)>Q_{2 L}^{*}+Q_{1 L}^{*}$ should be true, which is a contradiction. The proof for other cases are similar.

Thus, the solution given by Theorem 2 is unique.

\section{A5. Proof of Theorem 4}

Let $G_{A}$ and $G_{B}$ be the distribution functions of $D_{A}$ and $D_{B}$, respectively. $D_{A}$ stochastically dominates $D_{B}$. Thus, $G_{A}(x) \leq G_{B}(x)$ and $\bar{G}_{A}(x) \geq \bar{G}_{B}(x)$ for all $x$. Since $\bar{G}_{A}$ and $\bar{G}_{B}$ are decreasing functions, $\bar{G}_{A}^{-1}(y) \geq \bar{G}_{B}^{-1}(y)$ for all $y$. We define $\left(Q_{1 L}^{A}, Q_{1 H}^{A}, Q_{2 L}^{A}, Q_{2 H}^{A}\right)$ and $\left(Q_{1 L}^{B}, Q_{1 H}^{B}, Q_{2 L}^{B}, Q_{2 H}^{B}\right)$ as the equilibrium order quantities for $D_{A}$ and $D_{B}$, respectively.

Returning to the result of Theorem 2, we have three possible cases. Consider the equilibrium conditions in case (i). Now, since $\hat{s}$ is an increasing function, there exists $\delta_{2 H}=Q_{2 H}^{A}-Q_{2 H}^{B}=$ $\hat{s}\left(\bar{G}_{A}^{-1}\left(c_{2 H}\right)\right)-\hat{s}\left(\bar{G}_{B}^{-1}\left(c_{2 H}\right)\right) \geq 0$. Note that, the stock-out probability of firm 2 under high type does not change.

Now, by $\left(i_{2}\right)$,

$q \bar{G}_{A}\left(Q_{1 L}^{A}+Q_{2 H}^{A}\right)+(1-q) \bar{G}_{A}\left(s^{-1}\left(Q_{1 L}^{A}\right)\right)$ 
Table 5

Derivatives w.r.t. $c_{1 L}$.

\begin{tabular}{|c|c|c|c|c|}
\hline & Q & Conditions & $c_{1 L}$ & Sign \\
\hline \multirow{6}{*}{ (i) } & $Q_{2 H}$ & & 0 & \multirow{4}{*}{$\begin{array}{l}<0 \\
<0\end{array}$} \\
\hline & $Q_{1 L}$ & $\bar{G}\left(s^{-1}\left(Q_{1 L}\right)\right)>0$ & $-\frac{1}{-1}$ & \\
\hline & & $\bar{G}\left(s^{-1}\left(Q_{1 L}\right)\right)=0$ & $-\frac{q g\left(Q_{1 L}+\hat{s}\left(\bar{G}^{-1}\left(c_{2 H}\right)\right)\right)+(1-q)\left(s^{-1}\right)^{\prime} g\left(s^{-1}\left(Q_{1 L}\right)\right)}{1 \bar{C}^{-1}}$ & \\
\hline & $Q_{1 H}$ & & $0^{q g\left(Q_{1 L}+\hat{S}\left(\bar{G}^{-1}\left(c_{2 H}\right)\right)\right)}$ & \\
\hline & $Q_{2 L}$ & $\bar{G}\left(Q_{1 L}+Q_{2 L}\right)>0$ & $-\frac{(1-p) g\left(Q_{1 L}+Q_{2 L}\right)}{p g\left(Q_{1 H}+Q_{2 L}\right)+(1-p) g\left(Q_{1 L}+Q_{2 L}\right)}\left(\frac{\partial Q_{1 L}}{\partial c_{1 L}}\right)$ & $>0$ \\
\hline & & $\bar{G}\left(Q_{1 L}+Q_{2 L}\right)=0$ & 0 & \multirow{5}{*}{$\begin{array}{l}<0 \\
<0\end{array}$} \\
\hline \multirow[t]{4}{*}{ (ii) } & $Q_{1 L}$ & $\bar{G}\left(Q_{1 L}+Q_{2 L}\right)>0$ & 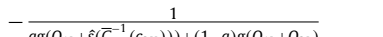 & \\
\hline & & $\bar{G}\left(Q_{1 L}+Q_{2 L}\right)=0$ & $\left.-\frac{q\left(Q_{1 L}+S(G\right.}{1}\left(c_{2 H}\right)\right)+(1-q) g\left(Q_{1 L}+Q_{2 L}\right)$ & \\
\hline & $Q_{1 H}$ & & 0 & \\
\hline & $Q_{2 L}$ & & 0 & \\
\hline \multirow[t]{4}{*}{ (iii) } & $Q_{1 L}$ & $\bar{G}\left(Q_{1 L}+Q_{2 L}\right)>0$ & $-\frac{1}{g \sigma\left(Q_{\mu}+\hat{S}\left(\bar{G}^{-1}\left(\mathcal{C}_{\mu}\right)\right)\right)+(1-g) g\left(O_{\mu}+\hat{S}\left(\bar{G}^{-1}\left(\mathcal{C}_{2}\right)\right)\right)}$ & \multirow{4}{*}{$\begin{array}{l}<0 \\
<0\end{array}$} \\
\hline & & $\bar{G}\left(Q_{1 L}+Q_{2 L}\right)=0$ & $-\frac{1}{q g\left(Q_{1 L}+\hat{s}\left(\bar{G}^{-1}\left(c_{2 H}\right)\right)\right)}$ & \\
\hline & $Q_{1 H}$ & & 0 & \\
\hline & $Q_{2 L}$ & & 0 & \\
\hline
\end{tabular}

Table 6

Derivatives w.r.t. $c_{1 H}$.

\begin{tabular}{|c|c|c|c|c|}
\hline & Q & Conditions & $\mathbf{c}_{1 \mathrm{H}}$ & Sign \\
\hline \multirow{5}{*}{ (i) } & $Q_{2 H}$ & & 0 & \multirow[b]{3}{*}{$<0$} \\
\hline & $Q_{1 L}$ & & 0 & \\
\hline & $Q_{1 H}$ & & $-\frac{1}{-10}$ & \\
\hline & $Q_{2 L}$ & $\bar{G}\left(Q_{1 L}+Q_{2 L}\right)>0$ & 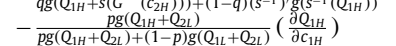 & $>0$ \\
\hline & & $\bar{G}\left(Q_{1 L}+Q_{2 L}\right)=0$ & $-\frac{\partial Q_{1 H}}{\partial c_{1 H}}$ & $>0$ \\
\hline \multirow[t]{3}{*}{ (ii) } & $Q_{1 L}$ & $\bar{G}\left(Q_{1 L}+Q_{2 L}\right)>0$ & 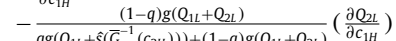 & $<0$ \\
\hline & $Q_{1 H}$ & $\bar{G}\left(Q_{1 L}+Q_{2 L}\right)=0$ & 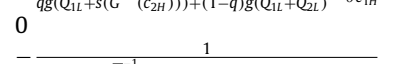 & $<0$ \\
\hline & $Q_{2 L}$ & $\begin{array}{l}\bar{G}\left(\hat{s}^{-1}\left(Q_{2 L}\right)\right)>0 \\
\bar{G}\left(\hat{s}^{-1}\left(Q_{2 L}\right)\right)=0\end{array}$ & $\begin{array}{l}-\overline{q g\left(Q_{1 H}+\hat{s}\left(\bar{G}^{-1}\left(c_{2 H}\right)\right)\right)+(1-q)\left(s^{-1}\right)^{\prime} g\left(s^{-1}\left(Q_{1 H}\right)\right)} \\
-\frac{p g\left(Q_{1 H}+Q_{2 L}\right)}{p g\left(Q_{1 H}+Q_{2 L}\right)+(1-p)\left(\hat{s}^{-1}\right)^{\prime} g\left(\hat{s}^{-1}\left(Q_{2 L}\right)\right)}\left(\frac{\partial Q_{1 H}}{\partial c_{1 H}}\right) \\
-\frac{g Q_{1 H}}{\partial c_{1 H}} \\
0\end{array}$ & $\begin{array}{l}<0 \\
>0 \\
>0\end{array}$ \\
\hline \multirow{3}{*}{ (iii) } & $\begin{array}{l}Q_{1 L} \\
Q_{1 H}\end{array}$ & $\bar{G}\left(O_{1 H}+O_{2 I}\right)>0$ & $\begin{array}{ll}0 \\
-\end{array}$ & \multirow{3}{*}{$\begin{array}{l}<0 \\
<0\end{array}$} \\
\hline & & $\bar{G}\left(Q_{1 H}+Q_{2 L}\right)=0$ & $-\frac{q g\left(Q_{1 H}+\hat{s}\left(\bar{G}^{-1}\left(c_{2 H}\right)\right)\right)+(1-q) g\left(Q_{1 H}+\hat{s}\left(\bar{G}^{-1}\left(c_{2 L}\right)\right)\right)}{q g\left(Q_{1 H}+\hat{s}\left(\bar{G}^{-1}\left(c_{2 H}\right)\right)\right)}$ & \\
\hline & $Q_{2 L}$ & & 0 & \\
\hline
\end{tabular}

$$
=q \bar{G}_{B}\left(Q_{1 L}^{B}+Q_{2 H}^{B}\right)+(1-q) \bar{G}_{B}\left(s^{-1}\left(Q_{1 L}^{B}\right)\right) .
$$

Since the stock-out probability of firm 2 under high type does not change and low type of firm 1 gets spillover only from high type of firm 2, the probability of firm 1's getting a spillover should not change.

Let $\delta_{1 L}=Q_{1 L}^{A}-Q_{1 L}^{B}$. We can rewrite the equilibrium condition as,

$$
\begin{aligned}
& q \bar{G}_{A}\left(Q_{1 L}^{A}+Q_{2 H}^{A}\right)+(1-q) \bar{G}_{A}\left(s^{-1}\left(Q_{1 L}^{A}\right)\right)=q \bar{G}_{B}\left(Q_{1 L}^{A}+Q_{2 H}^{A}\right. \\
& \left.-\delta_{1 L}-\delta_{2 H}\right)+(1-q) \bar{G}_{B}\left(s^{-1}\left(Q_{1 L}^{A}-\delta_{1 L}\right)\right),
\end{aligned}
$$

We know that for any $\left\{x_{1}, x_{2}\right\}$, if $\bar{G}_{A}\left(x_{1}\right)=\bar{G}_{B}\left(x_{2}\right)$ then $x_{1} \geq x_{2}$. Moreover, since the spillover probability does not change, $\bar{G}_{A}\left(s^{-1}\left(Q_{1 L}^{A}\right)\right) \geq \bar{G}_{B}\left(s^{-1}\left(Q_{1 L}^{A}\right)\right)$ should be satisfied. Thus, the difference between order quantities is positive, i.e., $\delta_{1 L} \geq 0$ and $Q_{1 L}^{A} \geq$ $Q_{1 L}^{B}$.

By a similar argument for $\left(i_{2}\right), \delta_{1 H}=Q_{1 H}^{A}-Q_{1 H}^{B} \geq 0$.

For $\left(i_{3}\right)$, we have

$$
\begin{aligned}
& p \bar{G}_{A}\left(Q_{2 L}^{A}+Q_{1 H}^{A}\right)+(1-p) \bar{G}_{A}\left(Q_{2 L}^{A}+Q_{1 L}^{*}\right)=p \bar{G}_{B}\left(Q_{2 L}^{B}\right. \\
& \left.\quad+Q_{1 H}^{A}-\delta_{1 H}\right)+(1-p) \bar{G}_{B}\left(Q_{2 L}^{B}+Q_{1 L}^{A}-\delta_{1 L}\right) .
\end{aligned}
$$

From previous argument, we know that the stock-out probability of firm 1 does not change with a stochastic increase in demand distribution. (Equilibrium order quantities increase to compensate the change in demand distribution.) Using a similar argument for $\left(i_{3}\right), \delta_{2 L}=Q_{2 L}^{A}-Q_{2 L}^{B} \geq 0$. Thus all the equilibrium order quantities

\begin{tabular}{|c|c|c|c|c|}
\hline & Q & Conditions & $\mathbf{c}_{2 \mathrm{~L}}$ & Sign \\
\hline \multirow{4}{*}{ (i) } & $Q_{2 H}$ & & 0 & \\
\hline & $Q_{1 L}$ & & 0 & \\
\hline & $Q_{1 H}$ & & 0 & \\
\hline & $Q_{2 L}$ & $\bar{G}\left(Q_{1 L}+Q_{2 L}\right)>0$ & $-\frac{1}{p g\left(Q_{11}+Q_{21}\right)+(1-p) g\left(Q_{11}+Q_{21}\right)}$ & $<0$ \\
\hline \multirow{4}{*}{ (ii) } & & $\bar{G}\left(Q_{1 L}+Q_{2 L}\right)=0$ & $-\frac{p g\left(Q_{1 H}+Q_{2 L}\right)+(1-p) g\left(Q_{1 L}+Q_{2 L}\right)}{p g\left(Q_{1 H}+Q_{2 L}\right)}$ & $<0$ \\
\hline & $Q_{1 L}$ & $\bar{G}\left(Q_{1 L}+Q_{2 L}\right)>0$ & $-\frac{(1-q) g\left(Q_{1 L}+Q_{2 L}\right)}{q g\left(Q_{1 L}+\hat{s}\left(\bar{G}^{-1}\left(c_{2 H}\right)\right)\right)+(1-q) g\left(Q_{1 L}+Q_{2 L}\right)}\left(\frac{\partial Q_{2 L}}{\partial c_{2 L}}\right)$ & $>0$ \\
\hline & & $\bar{G}\left(Q_{1 L}+Q_{2 L}\right)=0$ & 0 & \\
\hline & $Q_{1 H}$ & & 0 & \\
\hline \multirow{6}{*}{ (iii) } & $Q_{2 L}$ & $\bar{G}\left(\hat{s}^{-1}\left(Q_{2 L}\right)\right)>0$ & $-\frac{1}{g g\left(O_{H}+\hat{s}\left(\bar{G}^{-1}\left(c_{2 H}\right)\right)\right)+(1-q)\left(s^{-1}\right)^{\prime} g\left(s^{-1}\left(O_{1 H}\right)\right)}$ & $<0$ \\
\hline & & $\bar{G}\left(\hat{s}^{-1}\left(Q_{2 L}\right)\right)=0$ & $\left.\left.-\frac{q g\left(Q_{1+1}+S(G\right.}{p g\left(Q_{1 H}+Q_{2 L}\right)}\left(C_{2 H}\right)\right)\right)+(1-q)\left(S^{-1}\right) g\left(S^{-1}\left(Q_{1 H}\right)\right)$ & $<0$ \\
\hline & $Q_{1 L}$ & $\bar{G}\left(Q_{1 L}+Q_{2 L}\right)>0$ & $\frac{(1-q) \hat{s}^{\prime} g\left(Q_{1 L}+Q_{2 L}\right) / g\left(\bar{G}^{-1}\left(c_{2 L}\right)\right)}{g q\left(Q_{1}+\hat{s}\left(\bar{G}^{-1}\left(\mathcal{C}_{2 L}\right)\right)+(1-q) g\left(Q_{1}+\hat{s}\left(\bar{G}^{-1}\left(\mathcal{C}_{2}\right)\right)\right)\right.}$ & $>0$ \\
\hline & & $\bar{G}\left(Q_{1 L}+Q_{2 L}\right)=0$ & & \\
\hline & $Q_{1 H}$ & $\bar{G}\left(Q_{1 H}+Q_{2 L}\right)>0$ & $\frac{(1-q) \hat{s}^{\prime} g\left(Q_{1 H}+Q_{2 L}\right) / g\left(\bar{G}^{-1}\left(c_{2 L}\right)\right)}{q g\left(Q_{1 H}+\hat{s}\left(\bar{G}^{-1}\left(c_{2 H}\right)\right)\right)+(1-q) g\left(Q_{1 H}+\hat{s}\left(\bar{G}^{-1}\left(c_{2 L}\right)\right)\right)}$ & $>0$ \\
\hline & $Q_{2 L}$ & $\bar{G}\left(Q_{1 H}+Q_{2 L}\right)=0$ & $\begin{array}{l}0 \\
-\frac{\hat{S}^{\prime}}{g\left(\bar{G}^{-1}\left(c_{2 L}\right)\right)} \\
\end{array}$ & $<0$ \\
\hline
\end{tabular}
increase.

Similar proof for cases (ii) and (iii).
Table 7

Derivatives w.r.t. $c_{2 L}$.

\section{A6. Proof of Theorem 5}

As $s$ increases uniformly, $\hat{s}^{-1}$ increase, $\hat{s}$ and $s^{-1}$ decreases. From Theorem 2, as $s$ increases, $Q_{2 H}^{*}$ decreases.

From $\left(i_{1}\right)$,

$q \bar{G}^{A}\left(Q_{1 L}^{*}+Q_{2 H}^{*}\right)+(1-q) \bar{G}^{A}\left(s^{-1}\left(Q_{1 L}^{*}\right)\right)=c_{1 L}$.

If $s$ increases uniformly, $s^{-1}$ decreases. Hence, $Q_{1 L}$ should increase to satisfy the equilibrium condition. Similarly, $Q_{1 H}^{*}$ increases as $s$ increases.

From $\left(i_{3}\right)$,

$p \bar{G}^{A}\left(Q_{2 L}^{*}+Q_{1 H}^{*}\right)+(1-p) \bar{G}^{A}\left(Q_{2 L}^{*}+Q_{1 L}^{*}\right)=c_{2 L}$.

Since $Q_{1 L}^{*}$ and $Q_{1 H}^{*}$ increase, $Q_{2 L}^{*}$ should decrease to compensate. Similar argument applies for cases (ii) and (iii).

\section{A7. Comparative statics}

This section summarizes the comparative statics results for general demand distributions. But we need the following results.

First note that $s^{\prime}=\partial s(D) / \partial D>0$ and $\hat{s}^{\prime}=\partial \hat{s}(D) / \partial D>0$ since we assume both $s$ and $\hat{s}$ are increasing and deterministic functions. Then the derivative of the inverses of the split functions can be found by

$\left(s^{-1}\right)^{\prime}=\frac{\partial s^{-1}(Q)}{\partial Q}=\frac{1}{s^{\prime}\left(s^{-1}()\right)}>0$
$\left(\hat{s}^{-1}\right)^{\prime}=\frac{\partial \hat{s}^{-1}(Q)}{\partial Q}=\frac{1}{\hat{s}^{\prime}\left(\hat{s}^{-1}()\right)}>0$

We use these results to find the signs of derivatives of order quantities with respect to each parameter in the model (Table 510).

\section{A8. Equilibrium under uniform demand and linear market shares}

The equilibrium conditions under the assumption $D \sim \operatorname{Uniform}(0,1)$ are as follows:

$q\left(1-\min \left\{1, Q_{1 H}+Q_{2 H}\right\}\right)+(1-q)$

$\left(1-\min \left\{1, \max \left\{Q_{2 L} /(1-s), Q_{1 H}+Q_{2 L}\right\}\right\}\right)$

$+(1-q)\left(\max \left\{\min \left\{1, Q_{2 L} /(1-s)\right\}-\min \left\{1, Q_{1 H} / s\right\}, 0\right\}\right)=c_{1 H}$

$q\left(1-\min \left\{1, Q_{1 L}+Q_{2 H}\right\}\right)+(1-q)$

$\left(1-\min \left\{1, \max \left\{Q_{2 L} /(1-s), Q_{1 L}+Q_{2 L}\right\}\right)\right.$ 
Table 8

Derivatives w.r.t. $c_{2 H}$.

\begin{tabular}{|c|c|c|c|c|}
\hline & Q & Conditions & $c_{2 H}$ & Sign \\
\hline \multirow{7}{*}{ (i) } & $Q_{2 H}$ & & $-\frac{\hat{s}^{\prime}}{\sigma^{-1}\left(\tilde{C}^{2}\right)}$ & $<0$ \\
\hline & $O_{1}$ & $\bar{G}\left(s^{-1}\left(O_{y}\right)\right)>0$ & $\begin{array}{c}g\left(\bar{G}^{-1}\left(c_{2 H}\right)\right) \\
\quad \hat{s}^{\prime} g\left(Q_{1 L}+\hat{s}\left(\bar{G}^{-1}\left(c_{2 H}\right)\right)\right) / g\left(\bar{G}^{-1}\left(c_{2 H}\right)\right) \\
\end{array}$ & 0 \\
\hline & & $G\left(S-\left(Q_{1 L}\right)\right)>0$ & $\overline{q g\left(Q_{11}+\hat{s}\left(\bar{G}^{-1}\left(c_{2 H}\right)\right)\right)+(1-q)\left(s^{-1}\right)^{\prime} g\left(s^{-1}\left(Q_{1 L}\right)\right)}$ & $>0$ \\
\hline & & $\bar{G}\left(s^{-1}\left(Q_{1 L}\right)\right)=0$ & $\frac{\bar{S}^{\prime}}{\operatorname{gg}\left(\bar{G}^{-1}\left(C_{2}\right)\right)}$ & $>0$ \\
\hline & $Q_{1 H}$ & & 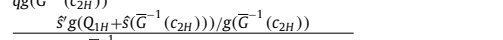 & $>0$ \\
\hline & $Q_{2 L}$ & $\bar{G}\left(Q_{1 L}+Q_{2 L}\right)>0$ & $\begin{array}{l}\overline{q g\left(Q_{1 H}+\hat{s}\left(\bar{G}^{-1}\left(c_{2 H}\right)\right)\right)+(1-q)\left(s^{-1}\right)^{\prime} g\left(s^{-1}\left(Q_{1 H}\right)\right)} \\
-\underline{p g\left(Q_{1 H}+Q_{2 L}\right) \partial Q_{1 H} / \partial c_{2 H}+(1-p) g\left(Q_{1 L}+Q_{2 L}\right) \partial Q_{1 L} / \partial c_{2 H}}\end{array}$ & $<0$ \\
\hline & & $\bar{G}\left(Q_{1 L}+Q_{2 L}\right)=0$ & $-\frac{\partial Q_{1 H}}{\partial C_{1 H}} \quad p g\left(Q_{1 H}+Q_{2 L}\right)+(1-p) g\left(Q_{1 L}+Q_{2 L}\right)$ & $<0$ \\
\hline \multirow[t]{5}{*}{ (ii) } & $Q_{1}$ & $\bar{G}\left(Q_{1 L}+Q_{2 L}\right)>0$ & $\underline{q \hat{s}^{\prime} g\left(Q_{1 L}+\hat{s}\left(\bar{G}^{-1}\left(c_{2 H}\right)\right)\right) / g\left(\bar{G}^{-1}\left(c_{2 H}\right)\right)+(1-q) g\left(Q_{1 L}+Q_{2 L}\right)\left(\partial Q_{2 L} / \partial c_{2 H}\right)}$ & $>0$ \\
\hline & & $\bar{G}\left(Q_{1 L}+Q_{2 L}\right)=0$ & $\hat{S}^{\prime} \quad q g\left(Q_{1 L}+\hat{s}\left(\bar{G}^{-1}\left(c_{2 H}\right)\right)\right)+(1-q) g\left(Q_{1 L}+Q_{2 L}\right)$ & $>0$ \\
\hline & $Q_{1 H}$ & & $\begin{array}{l}g\left(\bar{G}^{-1}\left(c_{2 H}\right)\right) \\
\quad \hat{s}^{2} g\left(Q_{1 H}+\hat{s}\left(\bar{G}^{-1}\left(c_{2 H}\right)\right)\right) / g\left(\bar{G}^{-1}\left(c_{2 H}\right)\right) \\
\end{array}$ & $>0$ \\
\hline & $Q_{2 L}$ & $\bar{G}\left(\hat{s}^{-1}\left(Q_{2 L}\right)\right)>0$ & 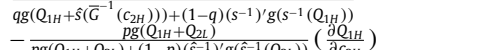 & $<0$ \\
\hline & & $\bar{G}\left(\hat{s}^{-1}\left(Q_{2 L}\right)\right)=0$ & $-\frac{\partial Q_{1 H}}{\partial c_{2 H}}$ & $<0$ \\
\hline \multirow{6}{*}{ (iii) } & $Q_{1 H}$ & $\bar{G}\left(Q_{1 L}+Q_{2 L}\right)>0$ & $q \hat{s}^{\prime} g\left(Q_{1 L}+Q_{2 H}\right) / g\left(\bar{G}^{-1}\left(c_{2 H}\right)\right)$ & $>0$ \\
\hline & & $\bar{G}\left(O_{1}+O_{U}\right)=0$ & $\overline{q g\left(Q_{1 L}+\hat{S}\left(\bar{G}^{-1}\left(c_{2 H}\right)\right)\right)+(1-q) g\left(Q_{1 L}+\hat{S}\left(\bar{G}^{-1}\left(c_{2 L}\right)\right)\right)}$ & $>0$ \\
\hline & & & $\overline{g\left(\bar{G}^{-1}\left(c_{2 H}\right)\right)}$ & $>0$ \\
\hline & $Q_{1 H}$ & $\bar{G}\left(Q_{1 H}+Q_{2 L}\right)>0$ & 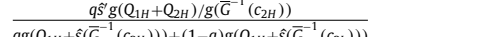 & $>0$ \\
\hline & & $\bar{G}\left(Q_{1 H}+Q_{2 L}\right)=0$ & 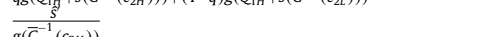 & $>0$ \\
\hline & $Q_{2 L}$ & & 0 & \\
\hline
\end{tabular}

Table 9

Derivatives w.r.t. $p$.

\begin{tabular}{|c|c|c|c|c|}
\hline & Q & Conditions & $\mathbf{p}$ & Sign \\
\hline (i) & $\begin{array}{l}Q_{2 H} \\
Q_{1 L} \\
Q_{1 H}\end{array}$ & & $\begin{array}{l}0 \\
0 \\
0\end{array}$ & \\
\hline (ii) & $\begin{array}{l}Q_{1 L} \\
Q_{1 H}\end{array}$ & $\begin{array}{l}\bar{G}\left(Q_{1 L}+Q_{2 L}\right)>0 \\
\bar{G}\left(Q_{1 L}+Q_{2 L}\right)=0 \\
\bar{G}\left(Q_{1 L}+Q_{2 L}\right)>0 \\
\bar{G}\left(Q_{1 L}+Q_{2 L}\right)=0\end{array}$ & 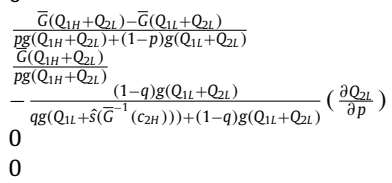 & $\begin{array}{l}>0 \\
>0 \\
<0\end{array}$ \\
\hline (iii) & $\begin{array}{l}Q_{1 L} \\
Q_{1 H} \\
Q_{2 L}\end{array}$ & $\begin{array}{l}\bar{G}\left(\hat{s}^{-1}\left(Q_{2 L}\right)\right)>0 \\
\bar{G}\left(\hat{s}^{-1}\left(Q_{2 L}\right)\right)=0\end{array}$ & $\begin{array}{l}\frac{\bar{G}\left(Q_{1 H}+Q_{2 L}\right)-\bar{G}\left(\hat{s}^{-1}\left(Q_{2 L}\right)\right)}{p g\left(Q_{1 H}+Q_{2 L}\right)+(1-p)\left(\hat{s}^{-1}\right)^{\prime} g\left(\hat{s}^{-1}\left(Q_{2 L}\right)\right)} \\
\frac{G\left(Q_{1 H}+Q_{2 L}\right)}{p g\left(Q_{1 H}+Q_{2 L}\right)} \\
0 \\
0 \\
0\end{array}$ & $\begin{array}{l}>0 \\
>0\end{array}$ \\
\hline
\end{tabular}

Table 10

Derivatives w.r.t. $q$.

\begin{tabular}{|c|c|c|c|c|}
\hline & Q & Conditions & $q$ & Sign \\
\hline & $Q_{2 H}$ & & 0 & \\
\hline \multirow[t]{5}{*}{ (i) } & $Q_{1 L}$ & $\bar{G}\left(s^{-1}\left(Q_{1 L}\right)\right)>0$ & $\frac{\bar{G}\left(Q_{1 L}+\hat{S}\left(\bar{G}^{-1}\left(c_{2 H}\right)\right)\right)-\bar{G}\left(s^{-1}\left(Q_{1 L}\right)\right)}{q g\left(Q_{1 L}+\hat{s}\left(\bar{G}^{-1}\left(c_{2 H}\right)\right)\right)+(1-q)\left(s^{-1}\right)^{\prime} g\left(s^{-1}\left(Q_{1 L}\right)\right)}$ & $>0$ \\
\hline & & $\bar{G}\left(s^{-1}\left(Q_{1 L}\right)\right)=0$ & $\frac{\bar{G}\left(Q_{1 L}+\hat{s}\left(\bar{G}^{-1}\left(c_{2 H}\right)\right)\right)}{q g\left(Q_{1 L}+\hat{s}\left(\bar{G}^{-1}\left(c_{2 H}\right)\right)\right)}$ & $>0$ \\
\hline & $Q_{1 H}$ & & $\bar{G}\left(Q_{1 H}+\hat{S}\left(\bar{G}^{-1}\left(c_{2 H}\right)\right)\right)-\bar{G}\left(s^{-1}\left(Q_{1 H}\right)\right)$ & $>0$ \\
\hline & $Q_{2 L}$ & $\bar{G}\left(Q_{1 L}+Q_{2 L}\right)>0$ & $\begin{array}{l}\overline{q g\left(Q_{11}+\hat{s}\left(\bar{G}^{-1}\left(c_{2 H}\right)\right)\right)+(1-q)\left(s^{-1}\right)^{\prime} g\left(s^{-1}\left(Q_{1 H}\right)\right)} \\
-\frac{p g\left(Q_{1 H}+Q_{2 L}\right) \partial Q_{1 H} / \partial q+(1-p) g\left(Q_{1 L}+Q_{2 L}\right) \partial Q_{1 L} / \partial q}{p g\left(Q_{1 H}+Q_{2 L}\right)+(1-p) g\left(Q_{1 L}+Q_{2 L}\right)}\end{array}$ & $<0$ \\
\hline & & $\bar{G}\left(Q_{1 L}+Q_{2 L}\right)=0$ & $-\frac{\partial Q_{1 H}}{\partial q}$ & $<0$ \\
\hline \multirow[t]{5}{*}{ (ii) } & $Q_{1 L}$ & $\bar{G}\left(Q_{1 L}+Q_{2 L}\right)>0$ & $\frac{\bar{G}\left(Q_{1 L}+\hat{s}\left(\bar{G}\left(c_{2 H}\right)\right)\right)-\bar{G}\left(Q_{1 L}+Q_{2 L}\right)-(1-q) g\left(Q_{1 L}+Q_{2 L}\right)\left(\partial Q_{2 L} / \partial q\right)}{q g\left(Q_{1}+\hat{s}\left(\bar{G}^{-1}\left(c_{2 H}\right)\right)\right)+(1-q) g\left(Q_{1 L}+Q_{21}\right)}$ & $>0$ \\
\hline & & $\bar{G}\left(Q_{1 L}+Q_{2 L}\right)=0$ & & $>0$ \\
\hline & $Q_{1 H}$ & & $\overline{\bar{G}}\left(Q_{1 H}+\hat{s}\left(\bar{G}^{-1}\left(c_{2 H}\right)\right)\right)-\bar{G}\left(s^{-1}\left(Q_{1 H}\right)\right)$ & $>0$ \\
\hline & $Q_{2 L}$ & $\bar{G}\left(\hat{s}^{-1}\left(Q_{2 L}\right)\right)>0$ & $\begin{array}{l}q g\left(Q_{1 H}+\hat{S}\left(\bar{G}^{-1}\left(c_{2 H}\right)\right)\right)+(1-q)\left(s^{-1}\right)^{\prime} g\left(s^{-1}\left(Q_{1 H}\right)\right) \\
-\frac{p g\left(Q_{1 H}+Q_{2 L}\right)}{p g\left(Q_{1 H}+Q_{2 L}\right)+(1-p)\left(\hat{s}^{-1}\right)^{\prime} g\left(\hat{s}^{-1}\left(Q_{2 L}\right)\right)}\left(\frac{\partial Q_{1 H}}{\partial q}\right)\end{array}$ & $<0$ \\
\hline & & $\bar{G}\left(\hat{s}^{-1}\left(Q_{2 L}\right)\right)=0$ & $-\frac{\partial Q_{1 H}}{\partial q}$ & $<0$ \\
\hline \multirow[t]{4}{*}{ (iii) } & $Q_{1 L}$ & $\bar{G}\left(Q_{1 L}+Q_{2 L}\right)>0$ & $\frac{\bar{G}\left(Q_{1 L}+\hat{s}\left(\bar{G}\left(c_{2 H}\right)\right)\right)-\bar{G}\left(Q_{1 L}+\hat{s}\left(\bar{G}\left(c_{2 L}\right)\right)\right)}{q g\left(Q_{1 L}+\hat{s}\left(\bar{G}^{-1}\left(c_{2 H}\right)\right)\right)+(1-q) g\left(Q_{1 L}+\hat{s}\left(\bar{G}^{-1}\left(c_{2 L}\right)\right)\right)}$ & $>0$ \\
\hline & & $\bar{G}\left(Q_{1 L}+Q_{2 L}\right)=0$ & $\frac{\bar{G}\left(Q_{1 L}+\hat{S}\left(\bar{G}\left(c_{2 H}\right)\right)\right)}{q g\left(Q_{1 L}+\hat{S}\left(\bar{G}^{-1}\left(c_{2 H}\right)\right)\right)}$ & $>0$ \\
\hline & $Q_{1 H}$ & $\bar{G}\left(Q_{1 H}+Q_{2 L}\right)>0$ & 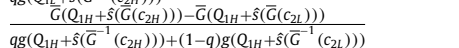 & $>0$ \\
\hline & $Q_{2 L}$ & $\bar{G}\left(Q_{1 H}+Q_{2 L}\right)=0$ & $\frac{\bar{G}\left(Q_{1 H}+\hat{s}\left(\bar{G}\left(c_{2 H}\right)\right)\right)}{q g\left(Q_{1 H}+\hat{S}\left(\bar{G}^{-1}\left(c_{2 H}\right)\right)\right)}$ & $>0$ \\
\hline
\end{tabular}

$$
\begin{aligned}
& +(1-q)\left(\operatorname { m a x } \left\{\min \left\{1, Q_{2 L} /(1-s)\right\}\right.\right. \\
& \left.\left.-\min \left\{1, Q_{1 L} / s\right\}, 0\right\}\right)=c_{1 L} \\
& Q_{2 H} /(1-s)=1-c_{2 H} \\
& p\left(1-\min \left\{1, \max \left\{Q_{1 H} / s, Q_{1 H}+Q_{2 L}\right\}\right\}\right. \\
& \left.+\max \left\{\min \left\{1, Q_{1 H} / s\right\}-\min \left\{1, Q_{2 L} /(1-s)\right\}, 0\right\}\right) \\
& +(1-p)\left(1-\min \left\{1, \max \left\{Q_{1 L} / s, Q_{1 L}+Q_{2 L}\right\}\right\}\right) \\
& +(1-p)\left(\max \left\{\min \left\{1, Q_{1 L} / s\right\}-\min \left\{1, Q_{2 L} /(1-s)\right\}, 0\right\}\right)=c_{2 L}
\end{aligned}
$$

Solution for $Q_{2 H}=(1-s)\left(1-c_{2 H}\right)$ is straight forward. However in order to obtain the solutions for $Q_{1 L}, Q_{1 H}$ and $Q_{2 L}$ we have to know the ordering for $Q_{1 L} / s, Q_{1 H} / s, Q_{2 L} /(1-s), 1$ and whether $Q_{1 L}+Q_{2 L}, Q_{1 H}+Q_{2 L}, Q_{1 L}+Q_{2 H}$ and $Q_{1 H}+Q_{2 H}$ are greater than 1 or not. We can summarize all the possibilities as:

$$
\begin{array}{lll}
\left\{\frac{Q_{1 L}}{s}>1, \frac{Q_{1 L}}{s} \leq 1\right\} & \left\{\frac{Q_{1 H}}{s}>1, \frac{Q_{1 H}}{s} \leq 1\right\} \\
\left\{\frac{Q_{2 L}}{s}>\frac{Q_{2 L}}{(1-s)}, \frac{Q_{1 L}}{s} \leq \frac{Q_{2 L}}{(1-s)}\right\} & \left\{\frac{Q_{1 H}}{s}>\frac{Q_{2 L}}{(1-s)}, \frac{Q_{1 H}}{s} \leq \frac{Q_{2 L}}{(1-s)}\right\} \\
\left\{Q_{1 L}+Q_{2 L}>1, Q_{1 L}+Q_{2 L} \leq 1\right\} & \left\{Q_{1 H}+Q_{2 L}>1, Q_{1 H}+Q_{2 L} \leq 1\right\} \\
\left\{Q_{1 L}+Q_{2 H}>1, Q_{1 L}+Q_{2 H} \leq 1\right\} & \left\{Q_{1 H}+Q_{2 H}>1, Q_{1 H}+Q_{2 H} \leq 1 .\right\}
\end{array}
$$

We have 512 different possibilities for $Q_{1 L}, Q_{1 H}$ and $Q_{2 L}$ each leading to a different region in the 7 dimensional space. However, the number of regions can be reduced to 8 regions as shown below.

First, if both of the players have a high type, then the total inventory cannot exceed 1 and if second firm has high type since he does not expect any spillover. This is simply due to the suboptimality of all values greater than 1 . Second, some of the conditions imply the others. For example, if $Q_{1 L} / s>1$ and $Q_{2 L} /(1-s)>1$ then $Q_{1 L}+Q_{2 L}>1$. Third, $Q_{2 L} /(1-s)>Q_{1 L} / s$ implies $Q_{2 L} /(1-s)>$ $Q_{1 H} / s$ since low type of a firm orders as much as high type of the firm due to submodularity. Similarly, $Q_{2 L} /(1-s) \leq Q_{1 H} / s$ implies $Q_{2 L} /(1-s) \leq Q_{1 L} / s$.

Using these kind of arguments we reduce the conditions to form 8 different regions. It can be shown that it is not possible to reduce the conditions further without making additional assumptions on the parameters.

\begin{tabular}{ll}
\hline Region & Conditions \\
\hline $\mathbf{1}$ & $\frac{Q_{1 L}}{s}>1, \frac{Q_{2 L}}{(1-s)}>1$ \\
$\mathbf{2}$ & $Q_{1 L}+Q_{2 L}>1, \frac{Q_{1 L}}{s} \leq 1$ \\
$\mathbf{3}$ & $Q_{1 L}+Q_{2 L} \leq 1, \frac{Q_{1 L}}{s} \leq \frac{Q_{2 L}}{(1-s)}$ \\
$\mathbf{4}$ & $Q_{1 L}+Q_{2 L}>1, \frac{Q_{2 L}}{(1-s)} \leq 1, \frac{Q_{1 H}}{s} \leq \frac{Q_{2 L}}{(1-s)}$ \\
$\mathbf{5}$ & $Q_{1 L}+Q_{2 L} \leq 1, \frac{Q_{1 L}}{s}>\frac{Q_{2 L}}{(1-s)}, \frac{Q_{1 H}}{s} \leq \frac{Q_{2 L}}{(1-s)}$ \\
$\mathbf{6}$ & $Q_{1 H}+Q_{2 L}>1, \frac{Q_{1 H}}{s}>\frac{Q_{2 L}}{(1-s)}$ \\
$\mathbf{7}$ & $Q_{1 L}+Q_{2 L}>1, \frac{Q_{1 H}}{Q_{2 L}} \leq 1, \frac{Q_{1 H}}{s}>\frac{Q_{2 L}}{(1-s)}$ \\
$\mathbf{8}$ & $Q_{1 L}+Q_{2 L} \leq 1, \frac{Q_{1 H}}{s}>\frac{Q_{2 L}}{(1-s)}$ \\
\hline
\end{tabular}

In each of the regions, the given inequalities simplify the equilibrium conditions leading to an easy computation of the equilibrium order quantities.

For Region 1, we reduce the equilibrium conditions to the following form:

$$
\begin{gathered}
q\left(1-Q_{1 H}-Q_{2 H}\right)+(1-q)\left(1-Q_{1 H} / s\right)=c_{1 H}, \\
q\left(1-Q_{1 L}-Q_{2 H}\right)=c_{1 L}, \\
Q_{2 H} /(1-s)=1-c_{2 H}, \\
p\left(1-Q_{1 H}-Q_{2 L}\right)=c_{2 L} .
\end{gathered}
$$

It is straightforward to find the order quantities for this region:

$$
\begin{array}{ll}
Q_{1 H}=\frac{\left(1-c_{1 H}-q(1-s)\left(1-c_{2 H}\right)\right)}{(q+(1-q) / s)} & Q_{1 L}=1-\frac{c_{1 L}}{q}-(1-s)\left(1-c_{2 H}\right), \\
Q_{2 H}=(1-s)\left(1-c_{2 H}\right) & Q_{2 L}=1-\frac{c_{2 L}}{p}-\frac{\left(1-c_{1 H}-q(1-s)\left(1-c_{2 H}\right)\right)}{(q+(1-q) / s)} .
\end{array}
$$

Now, by plugging these quantities into necessary inequalities, we obtain:

$$
\frac{Q_{1 L}}{s}>1 \quad \Rightarrow \quad 1-\frac{c_{1 L}}{q}-(1-s)\left(1-c_{2 H}\right)>s
$$




$$
\begin{aligned}
& \Rightarrow \frac{c_{1 L}}{q}-(1-s)\left(1-c_{2 H}\right)<1-s \\
& \Rightarrow \quad \frac{c_{1 L}}{q}-(1-s) c_{2 H}<0 \\
& \Rightarrow c_{1 L}<q(1-s) c_{2 H} \\
& \frac{Q_{2 L}}{(1-s)}>1 \quad \Rightarrow \quad 1-\frac{c_{2 L}}{p} \\
& -\frac{\left(1-c_{1 H}-q(1-s)\left(1-c_{2 H}\right)\right)}{(q+(1-q) / s)}>1-s \\
& \Rightarrow \frac{c_{2 L}}{p}+\frac{s\left(1-c_{1 H}-q(1-s)\left(1-c_{2 H}\right)\right)}{(1-(1-s) q)}<s \\
& \Rightarrow \quad \frac{c_{2 L}}{p}-\frac{s\left(c_{1 H}-q(1-s)\left(c_{2 H}\right)\right)}{(1-(1-s) q)}<0 \\
& \Rightarrow c_{2 L}<\frac{s p\left(c_{1 H}-q(1-s) c_{2 H}\right)}{1-(1-s) q}
\end{aligned}
$$$$
c_{1 L}<q(1-s) c_{2 H},
$$$$
c_{2 L}<\frac{s p\left(c_{1 H}-q(1-s) c_{2 H}\right)}{1-(1-s) q} \text {. }
$$

These conditions are necessary and sufficient, i.e., if these inequalities are satisfied, then equilibrium order quantities take the values

\begin{tabular}{|c|c|c|c|c|}
\hline & $Q_{1 L}^{\alpha}$ & $Q_{1 L}^{\beta}$ & $Q_{1 L}^{\gamma}$ & $Q_{1 L}^{\delta}$ \\
\hline$c_{1 L}$ & $-\frac{1}{q}$ & $-\frac{1}{(q+(1-q) / s)}$ & -1 & -1 \\
\hline$c_{1 \mathrm{H}}$ & 0 & 0 & $-\frac{s(1-s)(1-q) p}{(1-(1-s) q)(1-s p)}$ & 0 \\
\hline $\mathbf{p}$ & 0 & 0 & $\frac{s(1-s)(1-q)\left(\mathcal{C}_{2 l}-c_{1 H}+q(1-s)\left(c_{2 H}-\mathcal{C}_{2 L}\right)\right)}{(1-(1-s) q)(1-s p)^{2}}$ & 0 \\
\hline$c_{2 L}$ & 0 & 0 & $\frac{(1-s)(1-q)}{1-s p}$ & $(1-q)(1-s)$ \\
\hline$c_{2 \mathrm{H}}$ & $(1-s)$ & $\frac{s(1-s) q}{(1-s p)}$ & $\frac{q(1-s) p\left(1-q(1-s)-p s^{2}\right)}{(1-(1-s) q)(1-s p)}$ & $q(1-s)$ \\
\hline $\mathbf{q}$ & & $\frac{s(1-s)\left(C_{2 H}-C_{1 L}\right)}{(1-(1-s) q)^{2}}$ & $\frac{(1-s)\left((1-(1-s) q)^{2}\left(c_{2 H}-c_{2 L}\right)-p s^{2}\left(c_{2 H}-c_{1 H}\right)\right)}{\left(1-(1-s q)^{2}(1-p s)\right.}$ & $(1-s)\left(c_{2 H}-c_{2 L}\right)$ \\
\hline $\mathbf{s}$ & $\left(1-c_{2 H}\right)$ & $1-c_{2 H}+\frac{(1-q)\left(c_{2 H}-c_{11}\right)}{(1-(1-S) q)^{2}}$ & $\begin{array}{l}q\left(1-c_{2 H}\right)+(1-q)\left(\frac{1-s)(1-q)\left(1-c_{2 L}\right)}{(1-s p) c^{2}}+\frac{s(1-s) p q\left(1-c_{2 H}\right)}{(1-(1-s) q)(1-s p)}\right. \\
\left.+\frac{p\left(1-2 s+s^{2} p-(1-s)^{2} q\right)\left(1-c_{1 H}-q(1-s)\left(1-c_{2 H}\right)\right)}{(1-(1-s) q)^{2}(1-s p)^{2}}\right)\end{array}$ & $q\left(1-c_{2 H}\right)+(1-q)\left(1-c_{2 L}\right)$ \\
\hline
\end{tabular}
in Region 1.

In a similar fashion, we can obtain the conditions for all 8 regions. This is summarized in Fig. 1.

A9. Comparative statics under uniform demand and linear market shares

Thus, Region 1 can be characterized by two inequalities:

$$
Q_{1 L} \rightarrow
$$

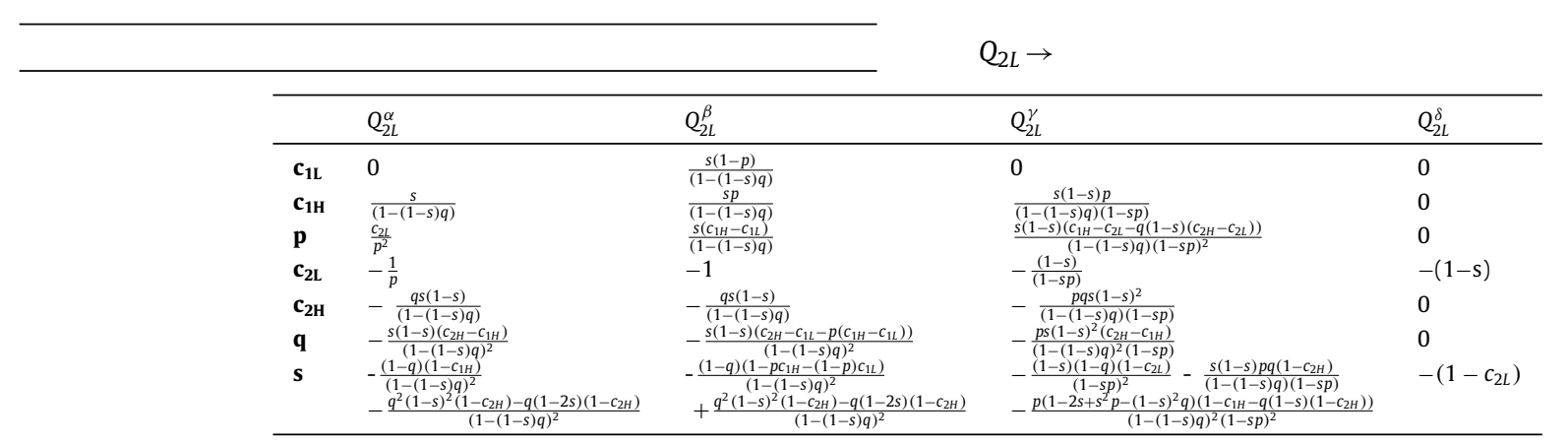

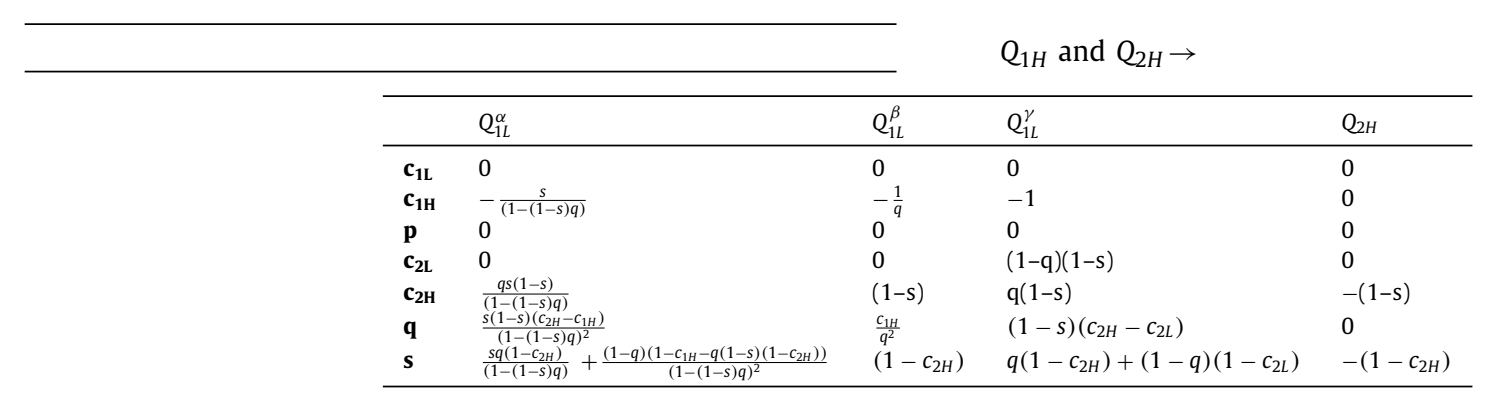




\section{References}

Anupindi, R., \& Bassok, Y. (1999). Centralization of stocks: Retailer vs. manufacturer. Management Science, 45(2), 178-191.

Athey, S. (2001). Single crossing properties and the existence of pure strategy equilibria in games of incomplete information. Econometrica, 69(4), 861-889.

Bernstein, F., \& Federgruen, A. (2003). Pricing and replenishment strategies in a distribution system with competing retailers. Operations Research, 51(3), 409426.

Bichler, M., Guler, K., \& Mayer, S. (2015). Split-award procurement auctions - can Bayesian equilibrium strategies predict human bidding behavior in multi-object auctions? Production and Operations Management, 24(6), 1012-1027.

Burke, G. J., Carrillo, J. E., \& Vakharia, A. J. (2007). Single versus multiple supplier sourcing strategies. European Journal of Operational Research, 182(1), 95-112.

Cachon, G. P. (2001). Stock wars: Inventory competition in a two-echelon supply chain with multiple retailers. Operations Research, 49(5), 658-674.

Cachon, G. P., \& Zipkin, P. (1999). Competitive and cooperative inventory policies in a two-stages supply chain. Management Science, 45(7), 936-953.

Cao, E., Wan, C., \& Lai, M. (2013). Coordination of a supply chain with one manufacturer and multiple competing retailers under simultaneous demand and cost disruptions. International Journal of Production Economics, 141(1), 425-433.

Hall, J., \& Porteus, E. (2000). Customer service competition in capacitated systems. Manufacturing \& Service Operations Management, 2(2), 144-165.

Jiang, H., Netessine, S., \& Savin, S. (2011). Robust newsvendor competition under asymmetric information. Operations Research, 59(1), 254-261.

Kerschbamer, R., \& Maderner, N. (1998). Are two a good representative for many? Journal of Economic Theory, 83(1), 90-104.

Lee, C.-Y., \& Yang, R. (2013). Compensation plan for competing salespersons under asymmetric information. European Journal of Operational Research, 227(3), 570-580.

Li, Q., \& Ha, A. Y. (2008). Reactive capacity and inventory competition under demand substitution. IIE Transactions, 40(8), 707-717.

Lippman, S. A., \& McCardle, K. F. (1997). The competitive newsboy. Operations Research, 45(1), 54-65.

Liu, L., Shang, W., \& Wu, S. (2007). Dynamic competitive newsvendors with service-sensitive demands. Manufacturing \& Service Operations Management, 9(1), 84-93.

Liu, W., Song, S., \& Wu, C. (2013). Impact of loss aversion on the newsvendor game with product substitution. International Journal of Production Economics, 141(1), 352-359.

Mahajan, S., \& van Ryzin, G. (2003). Inventory competition under dynamic consumer choice. Operations Research, 49(5), 646-657.
McGillivray, A., \& Silver, E. (1978). Some concepts for inventory control under substitutable demand. INFOR, 16(1), 47-63.

Milgrom, P. R., \& Roberts, J. (1990). Rationalizability learning and equilibrium in games with strategic complementarities. Econometrica, 58(6), 1255-1277.

Nagali, V., Hwang, J., Sanghera, D., Gaskins, M., Pridgen, M., Thurston, T., et al. (2008). Procurement Risk Management (PRM) at Hewlett-Packard company. Interfaces, 38(1), 51-60.

Netessine, S., \& Rudi, N. (2003). Centralized and competitive inventory models with demand substitution. Operations Research, 51(2), 329-335.

Netessine, S., Rudi, N., \& Wang, Y. (2006). Inventory competition and incentives to backorder. IIE Transactions, 38(11), 883-902.

Ovchinnikov, A., Moritz, B., \& Quiroga, B. F. (2015). How to compete against a behavioral newsvendor. Production and Operations Management. doi:10.1111/poms. 12361. to appear,

Parlar, M. (1988). Game theoretic analysis of the substitutable product inventory problem with random demands. Naval Research Logistics, 35(3), 397-409.

Sen, A., Yaman, H., Güler, K., \& Körpeoğlu, E. (2014). Multi-period supplier selection under price uncertainty. Journal of the Operational Research Society, 65(11) 1636-1648.

Serin, Y. (2007). Competitive newsvendor problems with the same Nash and Stackelberg solutions. Operations Research Letters, 35(1), 83-94.

Spiliotopoulou, E., Donohue, K., Gurbuz, M. C., \& Heese, H. S. (2018). Managing and reallocating inventory across two markets with local information. European Journal of Operational Research, 266(2), 531-542.

Topkis, D. (1979). Equilibrium points in nonzero-sum n-person submodular games. SIAM Journal of Control and Optimization, 17(6), 773-787.

Tunca, T. I., \& Wu, Q. (2009). Multiple sourcing and procurement process selection with bidding events. Management Science, 55(5), 763-780.

Vives, X. (1990). Nash equilibrium with strategic complementarities. Journal of Mathematical Economics, 19(3), 305-321.

Wang, Q. \& Parlar, M. (1994). A three-person game theory model arising in stochastic inventory control theory. European Journal of Operational Research, 76(1), 83-97.

van Zandt, T., \& Vives, X. (2007). Monotone equilibria in Bayesian games of strategic complementarities. Journal of Economic Theory, 134(1), 339-360.

Zhao, X., Atkins, D., Hu, M., \& Zhang, W. (2017). Revenue management under joint pricing and capacity allocation competition. European Journal of Operational Research, 257(3), 957-970. 